\title{
The 9-MilCA method as a rapid, partly automated protocol for simultaneously recording milk coagulation, curd firming, syneresis, cheese yield, and curd nutrients recovery or whey loss
}

\author{
C. Cipolat-Gotet, A. Cecchinato, ${ }^{1}$ G. Stocco, and G. Bittante \\ Department of Agronomy, Food, Natural resources, Animals and Environment (DAFNAE), University of Padova (Padua), viale dell'Università 16, \\ 35020 Legnaro, Italy
}

\begin{abstract}
The aim of this study was to propose and test a new laboratory cheesemaking procedure $[9-\mathrm{mL}$ milk cheesemaking assessment (9-MilCA)], which records 15 traits related to milk coagulation, curd firming, syneresis, cheese yield, and curd nutrients recovery or whey loss. This procedure involves instruments found in many laboratories (i.e., heaters and lacto-dynamographs), with an easy modification of the sample rack for the insertion of $10-\mathrm{mL}$ glass tubes. Four trials were carried out to test the 9-MilCA procedure. The first trial compared 8 coagulation and curd firming traits obtained using regular or modified sample racks to process milk samples from 60 cows belonging to 5 breeds and 3 farms (480 tests). The obtained patterns exhibited significant but irrelevant between-procedure differences, with better repeatability seen for 9-MilCA. The second trial tested the reproducibility and repeatability of the 7 cheesemaking traits obtained using the 9-MilCA procedure on individual samples from 60 cows tested in duplicate in 2 instruments (232 tests). The method yielded very repeatable outcomes for all 7 tested cheese yield and nutrient recovery traits (repeatability $>98 \%$ ), with the exception of the fresh cheese yield $(84 \%)$, which was affected by the lower repeatability $(67 \%)$ of the water retained in the curd. In the third trial (96 tests), we found that using centrifugation in place of curd cooking and draining (as adopted in several published studies) reduced the efficiency of whey separation, overestimated all traits, and worsened the repeatability. The fourth trial compared 9-MilCA with a more complex model cheese-manufacturing process that mimics industry practices, using $1,500-\mathrm{mL}$ milk samples (72 cows, 216 tests). The average results ob-
\end{abstract}

Received April 22, 2015.

Accepted November 2, 2015.

${ }^{1}$ Corresponding author: alessio.cecchinato@unipd.it tained from 9-MilCA were similar to those obtained from the model cheeses, with between-method correlations ranging from 78 to $99 \%$, except for the water retained in the curd $(\mathrm{r}=54 \%)$. Our results indicate that new 9-MilCA method is a powerful research tool that allows the rapid, inexpensive, and partly automated analysis processing 40 samples per day with 2 replicates each, using 1 lacto-dynamograph, 2 heaters, and 3 modified sample racks, and yields a complete picture of the cheesemaking process (e.g., milk gelation, curd firming, syneresis, and whey expulsion) as well as the cheese yield and the efficiency of energy or nutrients retention in the cheese or loss in the whey.

Key words: milk coagulation properties, cheesemaking, cheese yield, milk nutrients recovery in the curd, laboratory procedure

\section{INTRODUCTION}

The cheesemaking potential of milk can be defined by several traits, which may be measured at the laboratory level and reflect all subsequent stages of the process. Compared with the trials conducted in dairy plants, these laboratory testing procedures are characterized by the use of smaller milk samples, reduced experimental times and costs, and larger number of replications per day. The laboratory procedures can be divided into 3 main groups based on the traits analyzed and the cheesemaking phase assessed, as follows: (1) milk coagulation and curd cutting time (MCP, milk coagulation properties), (2) syneresis and water retention in the curd, and (3) cheese yield $(\% \mathbf{C Y})$ and milk nutrients recovery in the curd (REC, \%).

Several instruments have been used to assess coagulation process via different operating technologies (Laporte et al., 1998; O'Callaghan et al., 2002; Klandar et al., 2007). The lacto-dynamograph is the most commonly used instrument, especially for analyzing a large number of milk samples per day. This instrument 
mimics the cheesemaking process through the heating of milk and the addition of rennet and records both clot formation and firming, submerging a moving pendulum on a milk coagulating sample for $30 \mathrm{~min}$ (Annibaldi et al., 1977; McMahon and Brown, 1982). The output of this analysis is expressed by a curve whose width increases with the curd firmness. The traditional single-point traits obtained from a lacto-dynamographic analysis (i.e., the $\mathrm{MCP}$ ) are the interval between rennet addition (curd firmness $=0 \mathrm{~mm}$ ) and the first recorded increase in firmness (curd firmness $>1 \mathrm{~mm}$ ), which is defined as the rennet coagulation time (RCT, min), the interval between RCT and the point at which a curd firmness of $20-\mathrm{mm}$ is attained $\left(\mathbf{k}_{\mathbf{2 0}}, \mathbf{m i n}\right)$, and the curd firmness after $30 \mathrm{~min}$ from rennet addition $\left(\mathbf{a}_{\mathbf{3 0}}\right.$, $\mathrm{mm}$ ). An evolution of this technique (Bittante, 2011) involved the modeling of all curd firmness points $\left(\mathbf{C F}_{\mathbf{t}}\right)$ measured every $15 \mathrm{~s}$ to obtain the following 3 parameters for each milk sample: $\mathbf{R C T}_{\text {eq }}$, which is similar to $\mathrm{RCT}$ but is estimated using the CFt equation based on all the curd firmness points recorded for a given milk sample from the addition of rennet; the curd firming instant rate constant $\left(\mathbf{k}_{\mathbf{C F}}, \% / \mathrm{min}\right)$; and the asymptotical potential curd firmness $\left(\mathbf{C F}_{\mathbf{P}}, \% / \mathrm{min}\right)$.

Several laboratory procedures have been introduced for the assessment of curd syneresis using small quantities of milk per sample. Renault et al. (1997) described the use of image analysis to directly monitor curd shrinkage; the kinetic of syneresis was evaluated by gravimetric analysis of curd drainage (Castillo et al., 2000) and ultrasonic techniques (Taifi et al., 2006). Hansen et al. (2010) monitored syneresis using low-field nuclear magnetic resonance, and Fagan et al. (2007) monitored coagulation and syneresis by collecting nearinfrared absorbance recorded on a single wavelength.

Bittante et al. (2013b) estimated curd syneresis by prolonging the lacto-dynamographic test beyond the time (min) at which the curd firmness reached a maximum value $(\mathrm{mm})$ and began to decrease. Those authors interpreted this firmness reduction as the effect of whey expulsion, which allows the curd to freely move in the vessel; based on this, they proposed a syneresis instant rate constant $(\% / \mathrm{min})$. The use of these parameters has enabled the simultaneous estimation of the coagulation, curd firming, and syneresis.

The efficiency of the cheesemaking process is often defined by the cheese yield and milk nutrient recovery traits (Banks, 2007). Moving from commercial dairies to pilot plants and (especially) to laboratory facilities, labor and costs could be reduced together with an increment of the number of cheesemakings per day, although the processes used only partially mimic the operating conditions of the cheese industry. The laboratory protocols use different approaches depending on the objectives of the experiment and the type of model cheese. The protocols that most closely simulate the industrial dairy process are characterized by large milk samples, the cutting of the curd when it reaches a given firmness (assessed by an operator), the curd and whey are separated by draining and pressing, and the milk, whey, and curd are subjected to chemical analyses for the calculation of \%CY and REC traits. For example, Cipolat-Gotet et al. (2013) proposed a model cheese procedure that uses 1,500 -mL milk samples. They measured $3 \% \mathrm{CY}$ traits, expressing the weights of the fresh curd $\left(\mathbf{\%} \mathbf{C Y}_{\mathbf{C U R D}}\right)$, curd DM (\% $\left.\mathbf{C} \mathbf{Y}_{\text {SOLIDS }}\right)$, and water retained in the curd (\% $\left.\mathbf{C Y} \mathbf{Y}_{\text {WATER }}\right)$ as percentages of the weight of the processed milk, and 4 REC traits, expressing the curd contents of protein (REC PROTEIN $_{\text {Prot }}$, fat $\left(\mathbf{R E C}_{\mathbf{F A T}}\right)$, DM (REC $\left.\mathbf{C}_{\text {SOLIDS }}\right)$, and gross energy (REC $\mathbf{E N E R G Y}_{\text {EN }}$ ) as percentages of the corresponding nutrients in the processed milk.

In contrast, some simpler protocols use very small milk samples, fixed times between rennet addition and cutting, and centrifugation for whey separation. Othmane et al. (2002) described an efficient method capable of processing about 35 to 40 samples/h, in which $10-\mathrm{mL}$ samples of ewe milk were used to measure the fresh curd yield $\left(\% \mathrm{CY}_{\mathrm{CURD}}\right)$ but not the curd components. However, to the best of our knowledge, no protocol has yet been introduced that allows a large number of small-volume milk samples per day to be directly and simultaneously analyzed in terms of the traditional coagulation traits (MCP), $\mathrm{CF}_{\mathrm{t}}$ equation parameters, and cheesemaking traits (\% CY and REC).

The objectives of this work were (1) to propose a simple, high-throughput, and partly automated method [9-mL milk cheesemaking assessment (9-MilCA)] that permits the simultaneous analysis of $\mathrm{MCP}, \mathrm{CF}_{\mathrm{t}}, \% \mathrm{CY}$, and REC traits from small milk samples using a modified lacto-dynamograph; (2) to compare traditional (both measured and predicted) $\mathrm{MCP}$ and $\mathrm{CF}_{\mathrm{t}}$ model parameters recorded on standard and modified lactodynamographs; (3) to compare the use of centrifugation of coagulated samples versus cutting, cooking, and draining for the separation of whey from the curd; and (4) to compare the proposed partly automated method with a laboratory model cheese-manufacturing procedure that more closely resembles the industrial dairy process.

\section{MATERIALS AND METHODS}

\section{The 9-MilCA Method}

Principles of Protocol Development. The principles followed for the development of 9-MilCA were to use instruments available in many laboratories for the 
evaluation of milk coagulation properties (i.e., heaters and lacto-dynamographs); to simultaneously evaluate the coagulation and cheesemaking potential of milk samples; to mimic the procedures followed by the dairy industry as closely as possible; and to obtain information on the complete nutrient balance of the produced cheese, not just the fresh cheese yield trait. Many steps and individual parameters were evaluated during the development of this method, with the aim of optimizing it by balancing the workforce needed, the repeatability of the traits, and the similarity of the results to those obtained from industry-level experiments. Among the many choices made during method development, the most important for optimization were:

(a) to modify only the instrument sample rack to accommodate glass sample holders rather than modifying the instrument itself;

(b) to separate the curd from the whey by coagulum cutting, cooking, and draining rather than by centrifugation;

(c) to use Fourier-transform infrared (FTIR) spectroscopy calibration and not wet analyses for assessment of the milk and whey components;

(d) to analyze the whey rather than the curd composition when calculating the \%CY and REC traits $[($ milk - whey $) /$ milk $]$; and

(e) to set up a protocol with the aim of obtaining results comparable with those yielded by more complex laboratory methods that mimic the procedures of the dairy industry.

Sample rack modification (a) was intended to minimize any changes to the instruments (and thus the related costs), to decrease the potential alterations to the $\mathrm{MCP}-\mathrm{CF}_{\mathrm{t}}$ procedures and expected results, and to allow the curd extraction and its separation from the whey. The latter parameters were examined in the $\mathrm{MCP}-\mathrm{CF}_{\mathrm{t}}$ trial. Curd cooking and draining (b) was intended to ensure that the obtained \%CY and REC traits would be similar (in terms of both average and variability) to those typical of the dairy industry; this was tested in the centrifugation trial. Use of FTIR calibration (c) was made because FTIR spectra can be collected from small amounts of milk and whey (the whey obtained from 2 replicates of our method was sufficient), and because the predictions can be obtained very rapidly and inexpensively from a large number of samples. Difference of milk-whey weight components (d) was made because it guarantees better repeatability of the calculated \%CY and REC traits, as tested in the repeatability trial, and because the quantity of curd obtained is very small in the context of wet or infrared analysis. Finally, to seek results comparable with those obtained using more complex methods on larger samples (e) was tested by comparing our results with those from a manual model cheesemaking procedure that required $1,500-\mathrm{mL}$ samples, a 6 -h working time, and a 24-h total time span (representativeness trial).

Instruments Needed. To measure $\mathrm{MCP}$ and $\mathrm{CF}_{\mathrm{t}}$ parameters using a Formagraph (Foss Electric A/S, Hillerød, Denmark) or another similar lacto-dynamograph, the following equipment is required: (1) a sample rack with 10 wells (capacity $=10 \mathrm{~mL}$ ) representing each a measuring unit of the coagulation meter to simultaneously evaluate 10 milk samples per analysis session; (2) a plate heater for preheating the sample-filled sample rack; and (3) a measurement module (lacto-dynamograph) in which the sample rack is placed on a bar that conveys an internal reciprocating motion (i.e., a back-and-forth linear motion), and 10 pendulums are submerged in the milk-filled wells where they are free to oscillate within the samples as the sample rack moves. During $\mathrm{MCP}-\mathrm{CF}_{\mathrm{t}}$ analysis, the movement of the fluid milk does not cause oscillation of the pendulum between the stages of rennet addition and milk gelation. After gelation, the increased resistance of the moving milk gel applies force to the submerged pendulum; the resulting oscillation is registered every $15 \mathrm{~s}$ and the instrument software generates a diagram of coagulum firmness versus time $(\mathrm{mm} / \mathrm{min})$.

Instrument Modification. To assess the cheesemaking traits (i.e., the \% CY and REC traits) of the milk samples, we modified the sample rack. The original sample rack (Figure 1a) was an anodized aluminum parallelepiped cuboid (length $=267 \mathrm{~mm}$; width $=50 \mathrm{~mm}$; height $=49 \mathrm{~mm}$; weight $=1,448 \mathrm{~g})$ with 10 cylindrical wells or vats on its upper face. For our new method, the internal diameter of each well was expanded from 20 to $22 \mathrm{~mm}$ (Figure 1a), allowing us to insert a cylindrical glass tube with a conical tip (internal diameter $=19.6$ $\mathrm{mm}$; maximum external height $=44 \mathrm{~mm}$; thickness $=$ $1.2 \mathrm{~mm}$ ). As the internal volume of the glass tube was slightly smaller than that of the traditional wells (11.9 vs. $12.6 . \mathrm{cm}^{3}$ ), the modified sample rack was loaded with only $9 \mathrm{~mL}$ of milk (instead of $10 \mathrm{~mL}$ ) to maintain the same degree of pendulum submersion. The wells could not be enlarged further because of spacing constraints (limited space between wells).

In the present study, the 2 extreme positions of the sample rack (the first and the tenth wells or vats) were filled with distilled water $(9 \mathrm{~mL})$ and not used as measurement units because they had slightly slower heating (for both coagulation and curd cooking) compared with the other 8 positions. However, a slight increase in the 


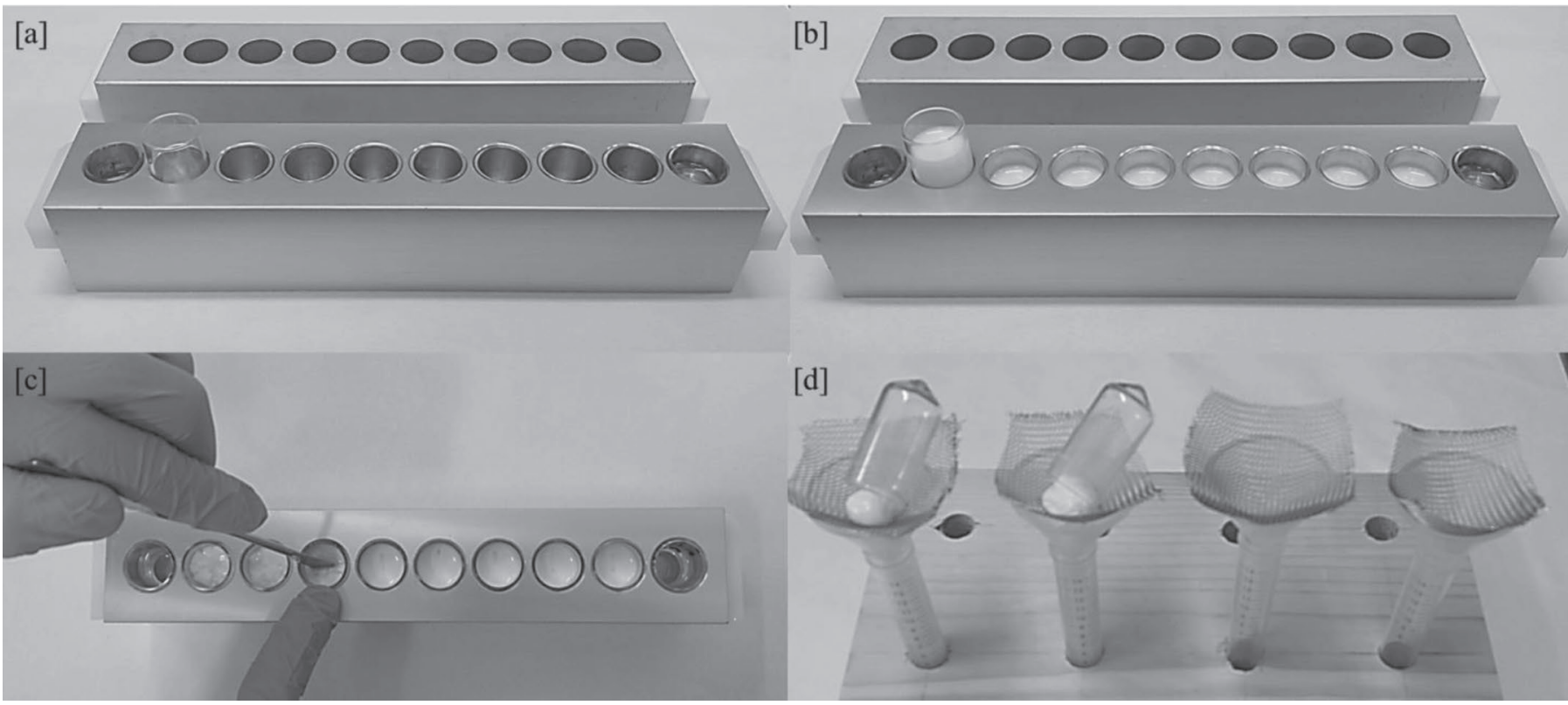

Figure 1. Traditional and the modified sample rack completed of the conical tubes (a), cylindrical glass tubes filled with the milk samples (b), manual cut after lactodynamographic analysis using a laboratory spatula (c), and a conical tube containing curd after whey separation (d).

heating duration and the inclusion of the vat number in the statistical model (which is recommended in any case) could allow all 10 vats to be used.

Heating, Coagulation, and Curd Firmness Measurements. The tested cheesemaking procedure was based on the steps summarized in Figure 2. The initial phases are almost the same as those of the traditional lacto-dynamographic test, save for the use of the modified sample rack and glass tubes. Briefly, each milk sample (9 instead of $10 \mathrm{~mL}$ ) was poured into a glass tube, and the tube was weighed using a precision scale, inserted into the sample rack (Figure 1b), heated up to $35^{\circ} \mathrm{C}$ for $15 \mathrm{~min}$, and gently mixed with $0.2 \mathrm{~mL}$ of a rennet solution [Hansen Standard 215, with $80 \pm$ $5 \%$ chymosin and $20 \pm 5 \%$ pepsin; 215 international milk clotting units (IMCU)/mL (Pacovis Amrein AG, Bern, Switzerland); diluted to $1.2 \%$ (wt/vol) in distilled water]. The sample rack was then transferred from the heater to the lacto-dynamograph and curd firmness was measured for 30 min from rennet addition.

Curd Cutting and Cooking. After $30 \mathrm{~min}$ from rennet addition (i.e., at the end of the lacto-dynamographic test), for milk samples that exhibited the gelation each clot (still inside the glass tube in the sample rack) was manually cut with 2 orthogonal vertical cut (cross-cut; Figure 1c) using a stainless steel spatula (total length $=175 \mathrm{~mm}$; spatula length $=40 \mathrm{~mm}$; spatula width $=$ $9 \mathrm{~mm}$ ). Once all samples were cut, the sample rack was moved to the heater (preheated at $70^{\circ} \mathrm{C}$ ) for $30 \mathrm{~min}$ of curd cooking. This step, which facilitated syneresis, was found to be necessary to obtain a whey expulsion similar to that typically seen in industrial cheesemaking. Preliminary tests were carried out to assess the temperature curve, and showed that the samples within the second to ninth tubes reached $55^{\circ} \mathrm{C}$ within $30 \mathrm{~min}$ of cooking. At 15 min of the cooking phase, each sample was subjected to further manual cutting. As this step is difficult to be standardized, the same technician, after an initial training, cut all the small curds obtained trying to standardize curd particles to the size of a rice grain.

Curd Draining and Whey Collection. For draining, each glass tube was removed from the sample rack and the curd was separated from the whey for $30 \mathrm{~min}$ at room temperature (about $20^{\circ} \mathrm{C}$ ). Figure $1 \mathrm{~d}$ shows the apparatus used for curd or whey separation and draining: a conical funnel containing a metallic net (1.5-mm holes) whose concave surface holds the curd (when the content of glass tube is reversed over the metallic net) while the whey was collected below in a plastic tube. Then the curd was slightly pressed with the same spatula used for curd-cutting to facilitate the whey expulsion. The obtained curd and whey were weighed using a precision scale. As the volume of whey produced from a single vat (about $7.5 \mathrm{~mL}$ ) was not sufficient for assessment of the chemical composition using an infrared spectrophotometer (FT2, Foss Electric A/S), 2 replicates of each milk sample were performed in consecutive wells of the same sample rack and the whey was pooled for chemical analysis. 
Traits Obtained. The 9-MilCA was used to obtain the following 15 technological milk traits for each processed milk sample: (1) 3 traditional single-observationpoint MCP (RCT, $\mathrm{k}_{20}$, and $\mathrm{a}_{30}$; Annibaldi et al., 1977; McMahon and Brown, 1982); (2) 3 model $\mathrm{CF}_{\mathrm{t}}$ (curd firmness as a function of time, $\mathrm{mm}$ ) parameters obtained over a 30 -min interval $\left(\mathrm{RCT}_{\mathrm{eq}}, \mathrm{k}_{\mathrm{CF}}\right.$, and $\mathrm{CF}_{\mathrm{P}}$; Bittante, 2011); (3) 2 traditional MCP predicted using the $\mathrm{CF}_{\mathrm{t}}$ model $\left(\mathrm{k}_{20} \mathrm{p}\right.$ and $\mathrm{a}_{30} \mathrm{p}$; Bittante, 2011); (4) 3 $\% \mathrm{CY}$ traits expressing the curd weight (obtained as the difference between the milk processed and the whey obtained) as a percentage of the processed milk weight $\left(\% \mathrm{CY}_{\mathrm{CURD}}, \% \mathrm{CY}_{\text {SOLIDS }}\right.$, and $\% \mathrm{CY}_{\text {WATER }}$; Cipolat-Gotet et al., 2013); and (5) 4 REC traits expressing curd nutrients in the curd as a percentage of the corresponding nutrient in the processed milk $\left(\mathrm{REC}_{\mathrm{PROTEIN}}, \mathrm{REC}_{\mathrm{FAT}}\right.$, $\mathrm{REC}_{\text {SOLIDS }}$, and REC $\mathrm{RENERG}_{\text {; }}$ Cipolat-Gotet et al., 2013).

Data Collection. The 4 objectives of our study were pursued through experimental trials performed on individual milk samples from 72 dairy cows reared in 4 farms

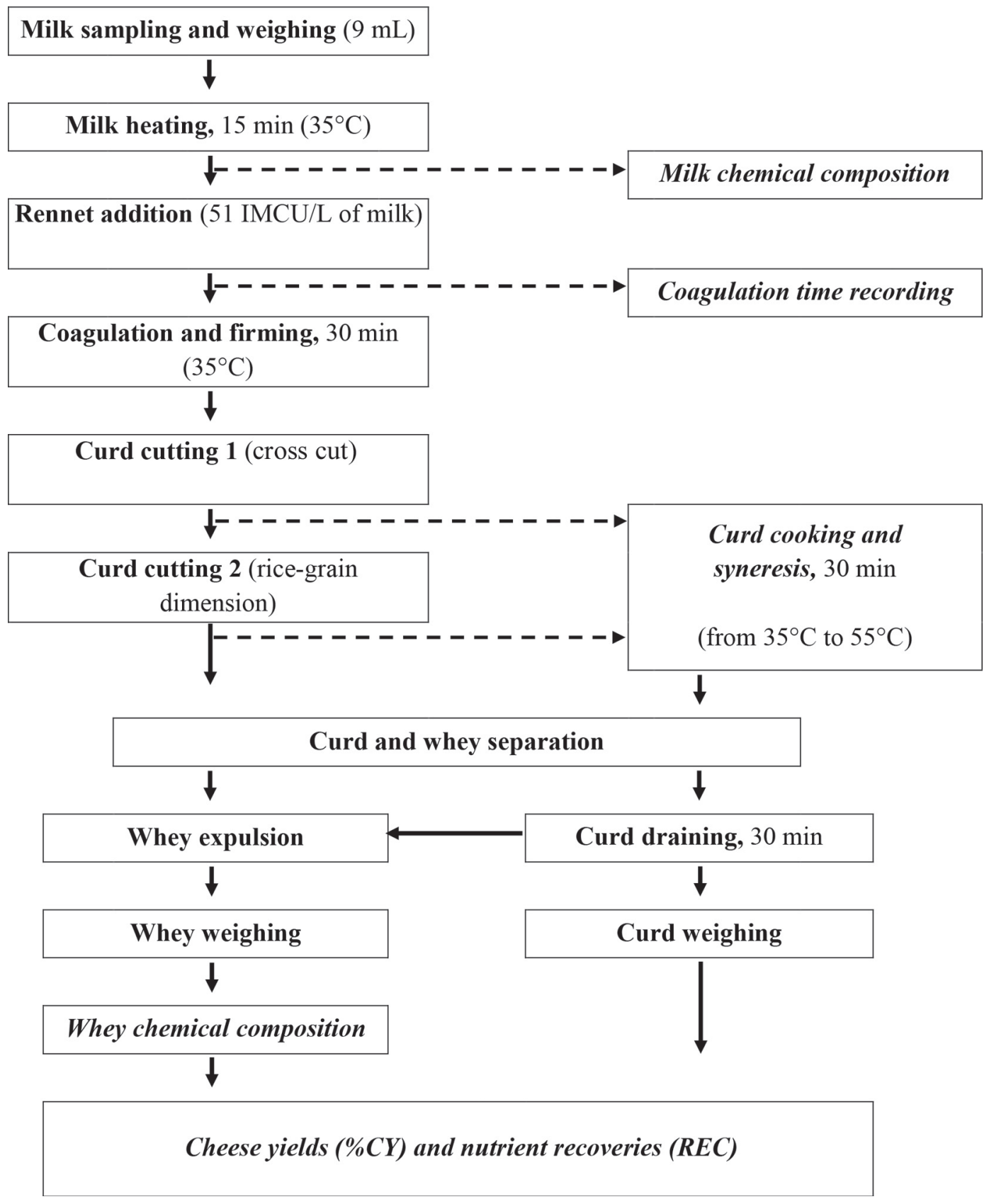

Figure 2. Flowchart for the 9-MilCA (9-mL milk cheesemaking assessment) method. IMCU = international milk clotting unit. 
located in Trento Province (northeastern Italian Alps). Sampling was carried out during the evening milkings over $4 \mathrm{~d}$ (20 animals each during the first 3 sessions and 12 animals during the fourth; 1 herd was sampled per session). The sampled cows were at different stages of lactation (15-612 DIM), differed in age (1-8 parity), and belonged to 5 different breeds, with each of the 4 sampled herds containing at least 2 breeds (in total 28 Brown Swiss, 22 Alpine Grey, 15 Rendena, 4 dualpurpose Simmental, and 3 Holstein-Friesian cows were selected). Samples $(2,000 \mathrm{~mL}$ of milk per cow) were collected without preservative, immediately placed at $4^{\circ} \mathrm{C}$, and then transported to the Milk Laboratory of the Department of Agronomy, Food, Natural Resources, Environment and Animals (DAFNAE) of the University of Padova (Legnaro, Padova, Italy). All samples were analyzed and processed on the following morning, within $20 \mathrm{~h}$ of collection. Each sample was analyzed for the fat, protein, casein, and lactose contents, using a MilkoScan FT2 (Foss Electric A/S). The SCC was measured using a Fossomatic FC counter (Foss Electric $\mathrm{A} / \mathrm{S}$ ) and log-transformed to the SCS as proposed by Ali and Shook (1980): SCS $=3+\log _{2}(\mathrm{SCC} / 100,000)$. Milk pH was assessed using a Crison Basic 25 electrode (Crison Instruments SA, Barcelona, Spain).

\section{$M C P-C F_{t}$ Trial Evaluating Coagulation and Curd Firming Results from Regular and Modified Sample Racks}

In the first experiment, we compared lacto-dynamographic analysis performed using the modified and standard (Cipolat-Gotet et al., 2012) sample racks. The protocols differed only in the type of sample rack: the analysis conditions were identical for both methods and all operations were performed by the same technician.

Individual bovine milk samples $(\mathrm{n}=60)$ were processed in 3 daily cheesemaking sessions. For each day, 20 samples (randomly divided into 5 groups 4 samples each) were analyzed. Two lacto-dynamographs were used, so each milk sample was subjected to 8 analyses (2 types of sample racks $\times 2$ replicates or glass tubes $\times 2$ instruments). A total of 480 lacto-dynamographic measures were performed ( 3 analysis sessions $\times 5$ group of cows $\times 4$ cows each $\times 2$ methods $\times 2$ instruments $\times$ 2 replicates). Eight coagulation and curd firming traits, the traditional MCP $\left(\mathrm{RCT}, \mathrm{k}_{20}\right.$ and $\left.\mathrm{a}_{30}\right)$, the model $\mathrm{CF}_{\mathrm{t}}$ parameters $\left(\mathrm{RCT}_{\text {eq }}, \mathrm{k}_{\mathrm{CF}}\right.$, and $\left.\mathrm{CF}_{\mathrm{P}}\right)$, and the traditional MCP predicted by the $\mathrm{CF}_{\mathrm{t}}$ model $\left(\mathrm{k}_{20 \mathrm{p}}\right.$ and $\left.\mathrm{a}_{30 \mathrm{p}}\right)$ were obtained.

Fifty-one of the 60 sampled cows $(85 \%)$ showed RCT below $30 \mathrm{~min}$ in all 8 replicates (4 replicates per method); among the remaining 9 cows, 36 single measures (480 in total; $7.5 \%$ ) failed to coagulate within $30 \mathrm{~min}$.
For these noncoagulating samples, $\mathrm{a}_{30}$ values equal to 0 were included in the statistical analysis (i.e., they were not considered as missing values). Lastly, for 86 $(18.0 \%)$ single lacto-dynamographic analysis, $\mathrm{k}_{20}$ was not recorded because the curd firmness failed to reach $20 \mathrm{~mm}$ within the test period.

\section{Repeatability Trial Evaluating Cheesemaking Measures Obtained Using 9-MilCA}

The second trial was conducted to test the withininstrument repeatability and the across-instrument reproducibility of the 7 cheesemaking traits $(3 \% \mathrm{CY}$ and 4 REC) assessed by 9-MilCA. In this trial, the analysis of $\mathrm{MCP}-\mathrm{CF}_{\mathrm{t}}$ was prolonged to include the processing of the curd on the modified sample rack. Sixty individual bovine milk samples were processed in 3 daily cheesemaking sessions, using 2 lacto-dynamographs. For each milk sample, 4 analyses (2 replicates or glass tubes $\times 2$ instruments $\times 1$ type of sample rack) were carried out. Thus, a total of 240 cheesemakings were performed (3 cheesemaking sessions $\times 5$ groups of cows $\times 4$ cows each $\times 2$ instruments $\times 2$ replicates or glass tubes). In some cases, milk samples failed to coagulate during the 30min lacto-dynamographic test but exhibited milk gelation during the curd-cooking phase; for these samples, the $\% \mathrm{CY}$ and REC traits were measured. Only 1 cow presented milk that failed to show any gelation during the entire cheesemaking process for all 4 replicates.

\section{Centrifugation Trial: Comparison to Cooking and Draining as a Strategy for Separating the Curd and Whey}

This third experiment was carried out to compare the 9-MilCA method with a simplified procedure that provides the use of centrifuge to remove the whey from the curd, in a step that replaces the stages after lactodynamographic analysis (i.e., double cutting of the curd, cooking and draining). The coagulated samples (still inside the glass tubes) were centrifuged (15 min, $1,800 \times \mathrm{g}$, and $20^{\circ} \mathrm{C}$; Allegra 25R; Beckman Coulter, Fullerton, CA) and the separation of the supernatant (whey) from the pellet (curd) was followed by a rest stage of $30 \mathrm{~min}$. The curd and whey produced by both methods were weighed, and the whey components were analyzed for calculation of \%CY and REC traits. Individual bovine milk samples $(\mathrm{n}=12 ; 3$ groups of 4 cows each) were processed via the 2 procedures using 2 lacto-dynamographs $(2$ replicates $\times$ instrument). This yielded 8 analyses per sample for a total of 96 cheesemakings ( 3 groups of cows $\times 4$ cows per group $\times 2$ instruments $\times 2$ methods $\times 2$ replicates or glass tubes). 


\section{Representativeness Trial Assessing 9-MilCA vs. Model Cheese Production for Measurement of \%CY and REC}

The fourth experiment compared the results obtained from 9-MilCA versus those from a laboratory procedure described by Cipolat-Gotet et al. (2013), which mimics the cheesemaking process carried out in a dairy plant. Briefly, $1,500 \mathrm{~mL}$ of milk was heated to $35^{\circ} \mathrm{C}$ in a small stainless steel vat, mixed with the same rennet solution used for the 9-MilCA procedure [Hansen Standard 215 , with $80 \pm 5 \%$ chymosin and $20 \pm 5 \%$ pepsin; 215 $\mathrm{IMCU} / \mathrm{mL}$ (Pacovis Amrein AG); diluted to 1.2\% (wt/ vol) in distilled water] and controlled for coagulation time. The curd from each vat was cut, drained, shaped into wheels, pressed, and salted at specified intervals from individual gelation time. The whey collected from each vat was weighed, sampled, and analyzed. The cheesemaking facility consisted of 4 water baths with precision thermostats and pumps for water mixing. Each water bath contained 5 stainless steel vats (capacity $=1,500 \mathrm{~mL}$ ). Thus, a single cheesemaking session allowed analysis of up to 20 (4 water baths $\times$ 5 vats) individual milk samples. Four cheesemaking sessions and 216 cheesemakings were carried out using the 72 individual milk samples described for the previous 2 trials (3 sessions, 20 samples per day; and 1 session, 12 samples) and following the 2 procedures.
For 9-MilCA, 2 repeated measures were carried out for each milk sample (4 cheesemaking sessions $\times 20$ or 12 cows each $\times 2$ replicates or glass tubes), whereas for the 1,500-mL-method, each milk sample was processed once 4 cheesemaking sessions $\times 20$ or 12 cows each $\times$ 1 replicate or vat). To compare the 2 procedures, the average values of the \%CY and REC traits from the 2 replicates of 9-MilCA were considered; thus, 144 data points were subjected to statistical analysis for each trait.

\section{Statistical Analysis}

The data obtained from the 4 experiments were subjected to statistical analysis using the SAS package (SAS Institute Inc., Cary, NC). Table 1 summarized the effects (fixed and random) included in each statistical model used to analyze the following response variables:

(1) MCP-CFt trial: RCT ( $\min ), \mathrm{k}_{20}(\mathrm{~min}), \mathrm{a}_{30}(\mathrm{~mm})$, $\mathrm{RCT}_{\text {eq }}(\mathrm{min}), \mathrm{CF}_{\mathrm{p}}(\mathrm{mm}), \mathrm{k}_{\mathrm{CF}}\left(\% \times \min ^{-1}\right), \mathrm{k}_{20 \mathrm{p}}$ $(\min )$, and $\mathrm{a}_{30 \mathrm{p}}(\mathrm{mm})$;

(2) repeatability trial: $\% \mathrm{CY}_{\mathrm{CURD}}, \quad \% \mathrm{CY}_{\text {SOLIDS }}$, $\% \mathrm{CY}_{\text {WATER}}, \mathrm{REC}_{\text {PROTEIN }}(\%), \operatorname{REC}_{\mathrm{FAT}}(\%)$, $\operatorname{REC}_{\text {SOLIDS }}(\%)$, and $\mathrm{REC}_{\text {ENERGY }}(\%)$;

(3) centrifugation trial: $\% \mathrm{CY}_{\mathrm{CURD}}, \% \mathrm{CY}_{\text {SOLIDS }}$, $\% \mathrm{CY}_{\text {WATER }}, \mathrm{REC}_{\text {PROTEIN }}(\%), \mathrm{REC}_{\mathrm{FAT}}(\%)$, $\operatorname{REC}_{\text {SOLIDS }}(\%)$, and REC ENERGY $(\%)$; and

Table 1. Summary of statistical models (and levels of each effect included) used for the 4 experimental trials

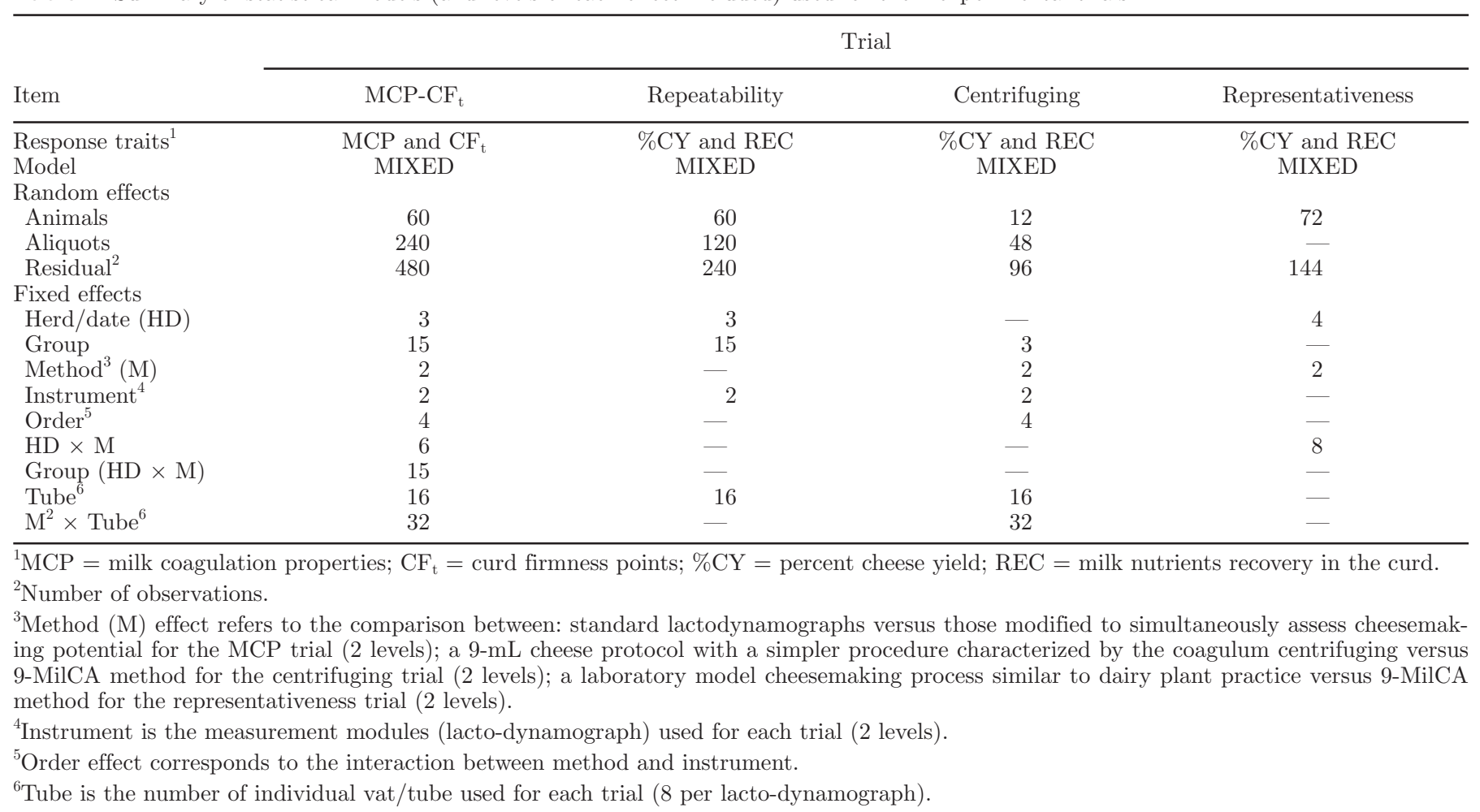


Table 2. For the MCP- $\mathrm{CF}_{\mathrm{t}}$ trial, descriptive statistics of traditional single-point measured milk coagulation properties $(\mathrm{MCP})$, of traditional $\mathrm{MCP}$ predicted by curd firming model $\left(\mathrm{CF}_{\mathrm{t}}\right)$, and of $\mathrm{CF}_{\mathrm{t}}$ model parameters recorded on standard lactodynamographs analysis and on 9-MilCA (9-mL milk cheesemaking assessment) ${ }^{1}$

\begin{tabular}{|c|c|c|c|c|c|}
\hline Item & $\mathrm{N}$ & Average & $\mathrm{SD}$ & $\mathrm{P} 5$ & P95 \\
\hline \multicolumn{6}{|l|}{ Measured MCP } \\
\hline RCT, min & 428 & 17.0 & 5.5 & 9.0 & 26.2 \\
\hline $\mathrm{k}_{20}, \min$ & 376 & 3.1 & 1.1 & 2.0 & 5.2 \\
\hline $\mathrm{a}_{30}, \mathrm{~mm}$ & 461 & 41.0 & 21.2 & 0.0 & 69.7 \\
\hline \multicolumn{6}{|l|}{ Predicted MCP } \\
\hline $\mathrm{k}_{20 \mathrm{p}}, \min$ & 371 & 3.0 & 1.2 & 1.5 & 5.0 \\
\hline $\mathrm{a}_{30 \mathrm{p}}, \mathrm{mm}$ & 444 & 41.8 & 21.5 & 0.0 & 69.9 \\
\hline \multicolumn{6}{|c|}{$\mathrm{CF}_{\mathrm{t}}$ model parameters } \\
\hline $\mathrm{RCT}_{\mathrm{eq}}$, min & 390 & 16.8 & 4.8 & 9.6 & 24.4 \\
\hline $\mathrm{CF}_{\mathrm{P}}, \mathrm{mm}$ & 387 & 62.7 & 11.4 & 43.7 & 78.9 \\
\hline $\mathrm{k}_{\mathrm{CF}}, \% \times \min ^{-1}$ & 386 & 14.2 & 5.9 & 7.2 & 23.6 \\
\hline
\end{tabular}

${ }^{1} \mathrm{P} 5=5$ th percentile; $\mathrm{P} 95=95$ th percentile; $\mathrm{RCT}=$ rennet coagulation time; $\mathrm{k}_{20}=$ curd firming rate as min to a curd firmness of $20 \mathrm{~mm} ; \mathrm{a}_{30}=$ curd firmness after $30 \mathrm{~min}$ from rennet addition; $\mathrm{CF}_{\mathrm{P}}=$ potential asymptotic curd firmness at infinite time; $\mathrm{k}_{\mathrm{CF}}=$ curd firming instant rate constant.

(4) representativeness trial: $\% \mathrm{CY}_{\mathrm{CURD}}, \% \mathrm{CY}_{\text {SOLIDS }}$, $\% \mathrm{CY}_{\text {WATER }}, \mathrm{REC}_{\text {PROTEIN }}(\%), \mathrm{REC}_{\mathrm{FAT}}(\%)$, $\operatorname{REC}_{\text {SOLIDS }}(\%)$, and REC ENERGY $(\%)$.

The homogeneity of the variances for the model residuals of the coagulation properties [i.e., the traditional MCP (both measured and predicted) and $\mathrm{CF}_{\mathrm{t}}$ parameters] obtained using the modified and standard sample racks $\left(\mathrm{MCP}-\mathrm{CF}_{\mathrm{t}}\right.$ trial) was assessed using Levene's test (Milliken and Johnson, 1984) on the residuals obtained from the statistical model summarized in Table 1. Levene's test was also used on the residual deviations of the cheesemaking traits obtained in the centrifugation trial to test the variance homogeneity of the \% CY and REC traits between the 2 methods (9-MilCA vs. centrifugation).

Linear regression (as applied by the SAS package) was used to explore the relationship between cheesemaking traits (\%CY and REC) measured by 9-MilCA, the 9-mL method with centrifugation, and model cheese-manufacturing process using water baths. The $F$-test was used to test the significance of any slope that deviated from unity and any intercept that was not zero $(P<0.05)$.

\section{RESULTS AND DISCUSSION}

\section{$M C P-C F_{t}$ Trial Evaluating the Coagulation and Curd Firming Results from Regular and Modified Sample Racks}

As our objective in developing the 9-MilCA method was to simultaneously obtain (from a single milk sample and instrument) both cheesemaking traits (\%CYs and RECs) and coagulation and curd firming properties $\left(\mathrm{MCP}-\mathrm{CF}_{\mathrm{t}}\right)$, we first tested whether modified sample racks and protocol could alter the gelation time or curd firming pattern compared with those obtained using the original sample racks and the standard lacto-dynamograph protocol in the same machine.

The traditional MCP (RCT, $\mathrm{k}_{20}$, and $\mathrm{a}_{30}$ ) and the modeled $\mathrm{CF}_{\mathrm{t}}$ parameters $\left(\mathrm{RCT}_{\mathrm{eq}}, \mathrm{CF}_{\mathrm{P}}\right.$, and $\left.\mathrm{k}_{\mathrm{CF}}\right)$ were assessed. All of the analysis conditions and operations were the same for both procedures, except for the sample rack type and the volume of milk sample (10 and $9 \mathrm{~mL}$ for the standard and 9-MilCA procedures, respectively). Table 2 presents descriptive statistics for the traditional single-point $\mathrm{MCP}$ and the $\mathrm{CF}_{\mathrm{t}}$ equation parameters determined using 120 curd firmness observations per sample (one every $15 \mathrm{~s}$ for $30 \mathrm{~min}$ ) according to the described mathematical model (Bittante, 2011). The same mathematical model was used to predict the traditional MCP $\left(\mathrm{k}_{20 \mathrm{p}}\right.$ and $\left.\mathrm{a}_{30 \mathrm{p}}\right)$ using all the $\mathrm{CFt}$ recorded on the entire lacto-dynamographic analysis. On average, the results presented in Table 2 showed slightly faster milk coagulation and curd firming rates compared with those more frequently observed (Bittante et al., 2012). For milk samples that failed to coagulate within the 30-min period of the lacto-dynamographic test, which are often called noncoagulating samples (Ikonen et al., 1999), no information about coagulation was available (RCT and $\mathrm{k}_{20}$ were not detected and $\mathrm{a}_{30}$ was set to 0 ) and were considered to be missing. The incidence of noncoagulating samples $(7.5 \%)$ in the present study was similar to the average values found for different bovine breeds, as reviewed by Bittante et al. (2012).

Table 3 presents the absolute deviations from the mean and the results of Levene's test of residuals (obtained by the ANOVA summarized in Table 4) comparing MCP measured using the standard versus modified sample racks. The average absolute deviations obtained using the 9-MilCA method were always smaller than those from the standard sample racks, although the difference reached statistical significance only for the 
Table 3. For the MCP-CF $\mathrm{t}_{\mathrm{t}}$ trial, results of Levene's test to evaluate heteroskedasticity of residual variance of milk coagulation properties (MCP) and of curd firming model $\left(\mathrm{CF}_{\mathrm{t}}\right)$ model parameters obtained using standard lactodynamographs or those modified to simultaneously assess cheesemaking potential of milk (9-MilCA; $9 \mathrm{~mL}$ milk cheesemaking assessment) ${ }^{1}$

\begin{tabular}{|c|c|c|c|}
\hline \multirow[b]{2}{*}{ Item } & \multicolumn{2}{|c|}{ Average absolute deviations } & \multirow{2}{*}{$\begin{array}{l}\text { Levene's test } \\
\quad(P \text {-value })\end{array}$} \\
\hline & Standard sample racks & Modified sample racks & \\
\hline \multicolumn{4}{|l|}{ Measured MCP } \\
\hline $\mathrm{RCT}, \min$ & 0.28 & 0.24 & NS \\
\hline $\mathrm{k}_{20}, \min$ & 0.25 & 0.22 & NS \\
\hline $\mathrm{a}_{30}, \mathrm{~mm}$ & 1.67 & 1.48 & NS \\
\hline \multicolumn{4}{|l|}{ Predicted MCP } \\
\hline $\mathrm{k}_{20 \mathrm{p}}, \min$ & 0.22 & 0.17 & $*$ \\
\hline $\mathrm{a}_{30 \mathrm{p}}, \mathrm{mm}$ & 1.54 & 1.17 & $* *$ \\
\hline \multicolumn{4}{|c|}{$\mathrm{CF}_{\mathrm{t}}$ model parameters } \\
\hline $\mathrm{RCT}_{\mathrm{eq}}, \min$ & 0.20 & 0.15 & ** \\
\hline $\mathrm{CF}_{\mathrm{P}}, \mathrm{mm}$ & 4.39 & 3.00 & $* *$ \\
\hline $\mathrm{k}_{\mathrm{CF}}, \% \times \min ^{-1}$ & 1.29 & 0.92 & $* *$ \\
\hline
\end{tabular}

${ }^{1} \mathrm{RCT}=$ rennet coagulation time; $\mathrm{k}_{20}=$ curd firming rate as min to a curd firmness of $20 \mathrm{~mm}$; $\mathrm{a}_{30}=$ curd firmness after $30 \mathrm{~min}$ from rennet addition; $\mathrm{CF}_{\mathrm{P}}=$ potential asymptotic curd firmness at infinite time; $\mathrm{k}_{\mathrm{CF}}=$ curd firming instant rate constant.

${ }^{*} P<0.05 ;{ }^{* *} P<0.01$.

$\mathrm{CF}_{\mathrm{t}}$ model parameters and the resulting predicted MCP. Thus, the modified sample racks yielded better repeatability for all MCP, which is particularly notable given that the repeatability of these traits is not very good (Caroli et al., 1990; Dal Zotto et al., 2008). Consistent with the results reported by Bittante (2011), the traditional MCP predicted by the model $\left(\mathrm{k}_{20 \mathrm{p}}\right.$ and $\mathrm{a}_{30 \mathrm{p}}$ ) showed better repeatability than the corresponding single-point observations $\left(\mathrm{k}_{20}\right.$ and $\left.\mathrm{a}_{30}\right)$. Moreover, the improvement of repeatability due to the use of the modified sample racks was particularly evident for these traits. Together, the use of our modified sample racks and $\mathrm{CF}_{\mathrm{t}}$ model prediction reduced the average absolute deviations for both MCP by about $30 \%$ and approximately halved the expected residual variances, as compared with the standard technique.

Table 4 shows the results of the variance analysis for the evaluation of milk coagulation by the 2 methods. The fixed effects of herd or date and group were often significant, and the random effect of the individual animal (on which the fixed effects were tested) was high, as expected.

The effect of the method (tested on aliquot variance) was significant for most of the considered traits, also because of the large number of lacto-dynamographic tests carried out. Despite the statistical significance of this factor, the differences between the least squares means of the 2 methods were negligible (e.g., for $\mathrm{RCT}, \mathrm{k}_{20}$, and $\mathrm{a}_{30}$ they were $18 \mathrm{~s}, 5 \mathrm{~s}$, and $1.51 \mathrm{~mm}$, respectively; Figure 3). Combination of the significant between-method differences observed for the $\mathrm{CF}_{\mathrm{t}}$ model parameters yielded the pattern illustrated in Figure 4. The average pattern was not very different, reflecting a slight acceleration of the curd firming process with use of the modified sample rack.

The used instrument was associated with modest (but significant) differences for the $\mathrm{CF}_{\mathrm{t}}$ model parameters, but not their derived predicted traits. The order of the analyzed samples, including the method $\times$ instrument interaction, was modest (but significant) for the measured and predicted RCT and $\mathrm{a}_{30}$. The method $x$ herd or date interaction was significant only for the traditional MCP, whereas the group within method $x$ instrument interaction was never significant. The differences between the 2 methods and their interactions with other factors known to affect the reproducibility of lacto-dynamographic analysis were modest and much lower than those induced by other modifications of the procedure (Stocco et al., 2015). Moving to the variation between replicates (which was tested on the residual variance), Table 4 shows that, as often happens (Ikonen et al., 2004; Tyrisevä et al., 2004), the effect of the sample rack position (tube, pendulum) was significant but the interaction between the method and the sample rack position was not.

\section{Repeatability Trial for the Cheesemaking Traits}

Descriptive statistics for the milk components $(\mathrm{n}=$ 60 individual samples), \%CY and REC ( $\mathrm{n}=232$ measures) observed in the second trial are given in Table 5. The milk samples used to test the 9-MilCA method presented a large variability, reflecting different dairy systems, different breeds within herds, and different parities and stages of lactation among the sampled cows. 
CIPOLAT-GOTET ET AL.

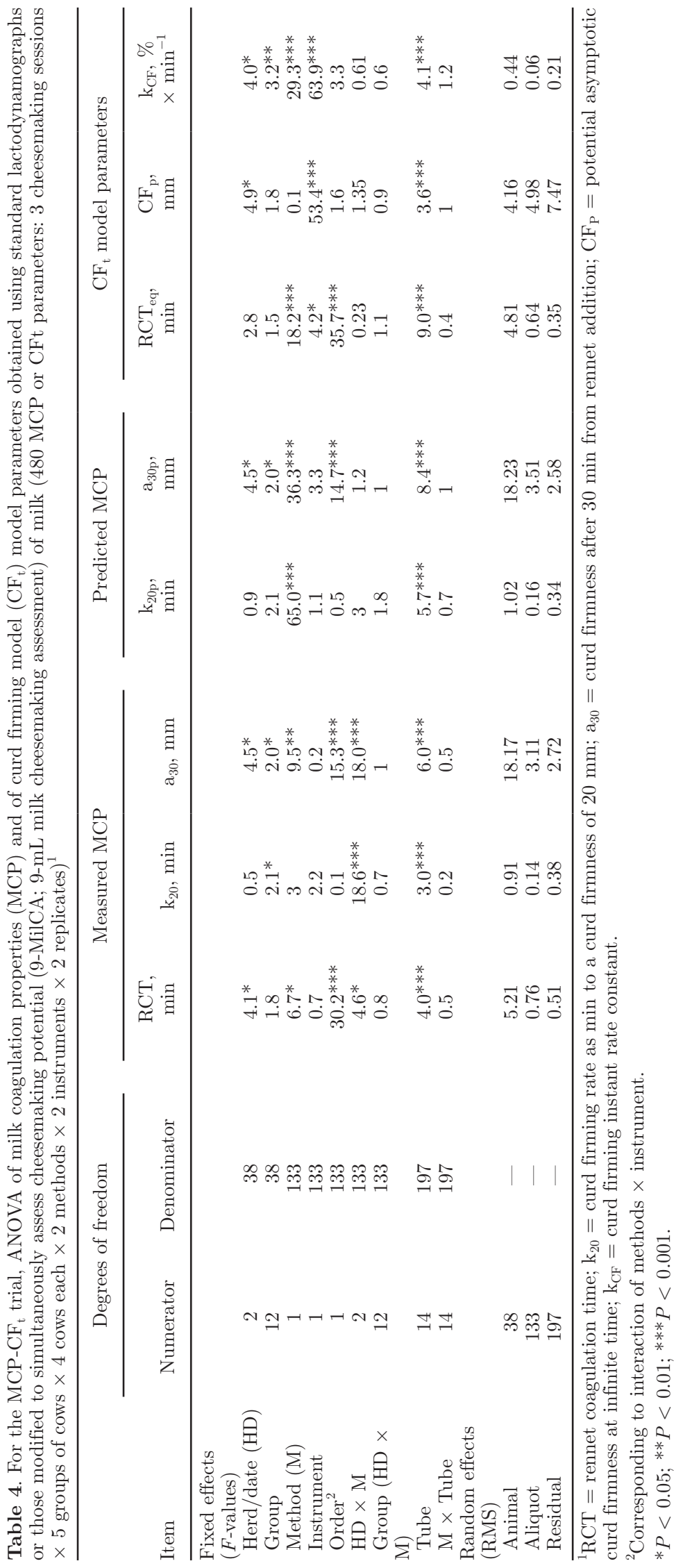


[a]

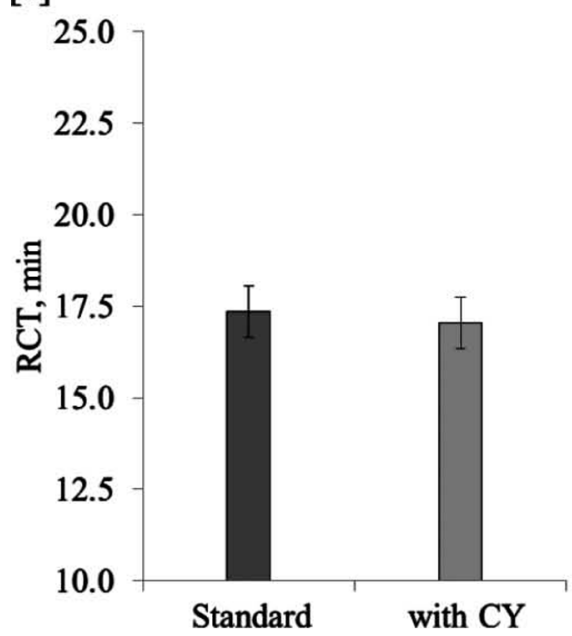

[b]

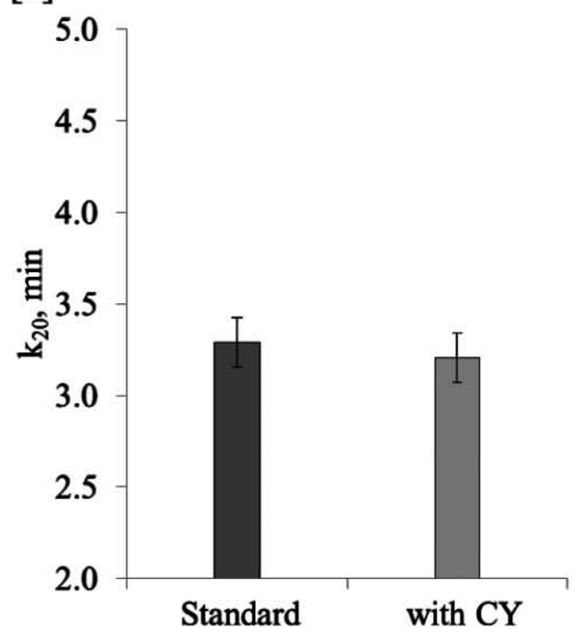

[c]

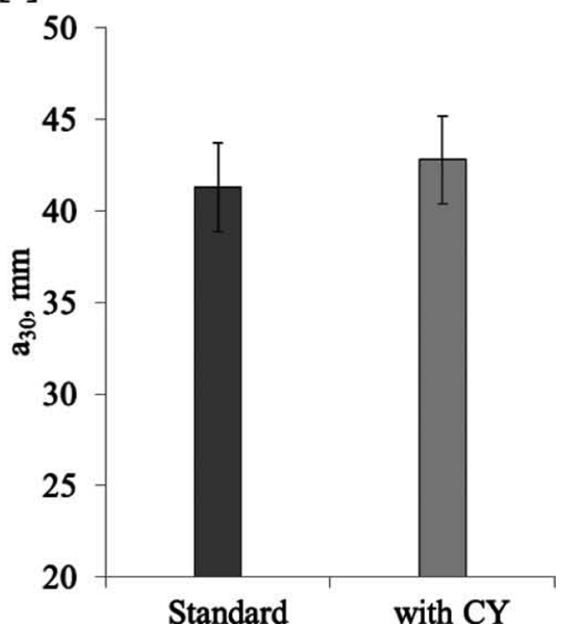

Figure 3. Traditional milk coagulation properties [rennet coagulation time (RCT), a; curd firmness at 20 min $\left(\mathrm{k}_{20}\right)$, b; curd firmness 30 min from rennet addition $\left.\left(\mathrm{a}_{30}\right), \mathrm{c}\right]$ obtained by the least square method using standard lactodynamographs (standard), and the 9-MilCA (9$\mathrm{mL}$ milk cheesemaking assessment) protocol [with cheese yield (CY)], respectively.
The 9-MilCA method is based on weighing (milk, curd, and whey) and analyzing the composition (milk and whey) of the inputs and outputs of the cheesemaking process, and yields information on traits that analytically describe the cheesemaking potential of the milk (\%CY and REC). Notably, \%CY WATER defines the retention of water in the curd and (conversely) its expulsion in the whey, providing an overview of the syneresis capability of the processed milk. As expected given the variability of the milk samples processed, the cheesemaking traits showed large variability (Table 5). The distributions of the \%CY and REC were quite normal, presenting kurtosis and skewness values close to 0 (data not shown). The $\% \mathrm{CY}_{\mathrm{CURD}}$ showed a standard deviation of $1.82 \%$ due more to a high variability in water retention $\left(\mathrm{SD}\right.$ of $\% \mathrm{CY}_{\mathrm{WATER}}=1.28 \%$ ) rather than the $\mathrm{DM}$ incorporated in the curd $(\mathrm{SD}=0.78 \%)$. During method development, the timings and types of all operations or stages of the cheesemaking process were established to obtain a curd with a moisture content not much greater than $50 \%$, as this is a common preripening value obtained in the cheese industry for many marketed cheeses (Verdier-Metz et al., 2000; Milesi et al., 2007; Martin et al., 2009). The greater average value of $\% \mathrm{CY}_{\text {WATER }}$ compared with $\% \mathrm{CY}_{\text {SOLIDS }}$ (Table 2) yielded a curd moisture content of $58.0 \%$ (SD $=3.3 \%$ )

In the literature, when the cheesemaking potential is assessed using a small quantity of milk $(\leq 50 \mathrm{~mL})$ at the laboratory level, the curd is often separated from the whey via centrifugation. In this case, the chemical composition of the cheesemaking outputs are not analyzed due to the small quantities of curd and whey obtained; thus, only $\% \mathrm{CY}_{\mathrm{CURD}}$ can be measured. This is true for

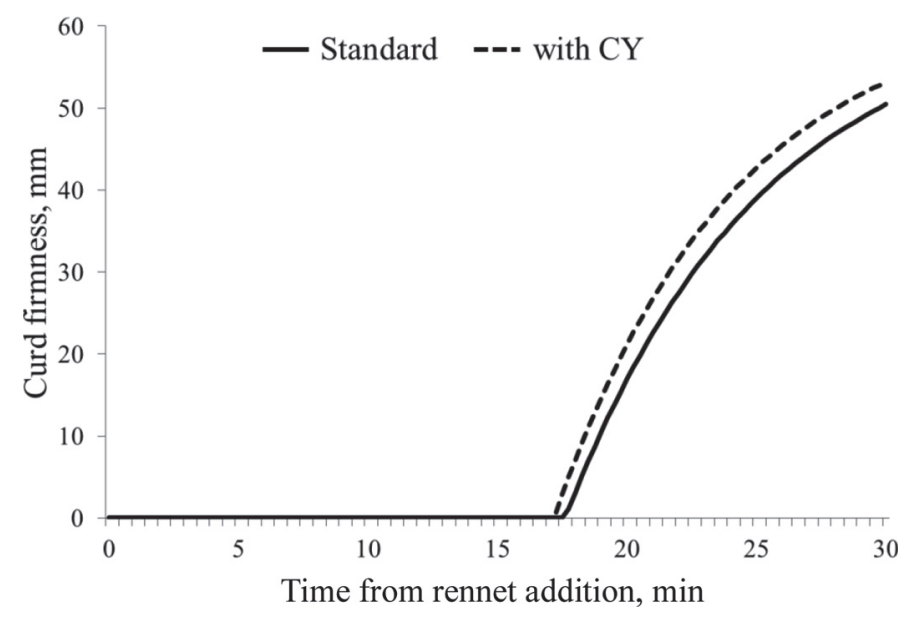

Figure 4. Curd firmness models obtained by least square method, using standard lactodynamographs (standard), and the 9-MilCA MilCA (9-mL milk cheesemaking assessment) protocol [with cheese yield $(\mathrm{CY})]$, respectively. 
Table 5. For the repeatability trial, descriptive statistics ${ }^{1}$ of milk composition, cheese yield traits (\%CY, expressed in \% of processed milk), and of milk nutrients recovery in curd (REC, expressed as \% of the same nutrient in milk) obtained by 9-MilCA ${ }^{2}$ method $\left(232^{3}\right.$ cheesemakings: 3 cheesemaking sessions $\times 5$ groups of cows $\times 4$ cows each $\times 2$ instruments $\times 2$ replicates/tubes $)^{4}$

\begin{tabular}{|c|c|c|c|c|c|}
\hline Item & $\mathrm{N}$ & Average & $\mathrm{SD}$ & $\mathrm{P} 5$ & P95 \\
\hline \multicolumn{6}{|l|}{ Milk composition } \\
\hline Protein, \% & 60 & 3.53 & 0.38 & 2.98 & 4.12 \\
\hline Casein, \% & 60 & 2.76 & 0.29 & 2.33 & 3.20 \\
\hline Casein number, \% & 60 & 78.2 & 1.1 & 76.3 & 79.8 \\
\hline Fat, $\%$ & 60 & 3.49 & 0.60 & 2.62 & 4.26 \\
\hline Lactose, \% & 60 & 4.85 & 0.22 & 4.40 & 5.14 \\
\hline $\mathrm{DM}, \%$ & 60 & 12.98 & 0.78 & 11.80 & 14.07 \\
\hline SCS & 60 & 3.65 & 1.50 & 1.03 & 5.62 \\
\hline \multicolumn{6}{|l|}{ Cheese yields (\%CY) } \\
\hline$\% \mathrm{CY}_{\mathrm{CURD}}$ & 232 & 15.18 & 1.82 & 12.53 & 18.13 \\
\hline$\% \mathrm{CY}_{\text {SOLIDS }}$ & 232 & 6.35 & 0.78 & 4.95 & 7.65 \\
\hline$\% \mathrm{CY}_{\text {WATER }}$ & 232 & 8.82 & 1.28 & 6.93 & 10.98 \\
\hline \multicolumn{6}{|c|}{ Nutrient recovery (REC) } \\
\hline $\mathrm{REC}_{\text {PROTEIN }} \%$ & 232 & 77.3 & 2.3 & 72.5 & 79.9 \\
\hline $\mathrm{REC}_{\mathrm{FAT}}, \%$ & 232 & 80.9 & 8.5 & 59.7 & 88.5 \\
\hline $\mathrm{REC}_{\text {SOLIDS }}, \%$ & 232 & 48.7 & 3.8 & 41.0 & 54.2 \\
\hline $\mathrm{REC}_{\text {ENERGY }}, \%$ & 232 & 61.6 & 4.5 & 50.3 & 66.7 \\
\hline
\end{tabular}

${ }^{1} \mathrm{P} 5=5$ th percentile; P95 $=95$ th percentile.

${ }^{2}$ 9-MilCA $=9$-mL milk cheesemaking assessment.

${ }^{3}$ Eight cheesemaking procedures excluded because of incomplete data.

${ }^{4} \% \mathrm{CY}_{\mathrm{CURD}}=$ fresh cheese yield; $\% \mathrm{CY}_{\text {SOLIDS }}=$ total solids cheese yield; $\% \mathrm{CY}_{\mathrm{WATER}}=$ water retained in the curd; $\mathrm{REC}_{\mathrm{PROTEIN}}, \%=$ protein retention in the curd; $\mathrm{REC}_{\mathrm{FAT}}, \%=$ fat retention; $\mathrm{REC}_{\mathrm{SOLIDS}}, \%=$ total solids retention; $\mathrm{REC}_{\mathrm{ENERGY}}, \%=$ energy retention.

the study proposed by Othmane et al. (2002), which assessed $\% \mathrm{CY}_{\mathrm{CURD}}$ using $10-\mathrm{mL}$ individual samples of ewe milk and found a very high $\% \mathrm{CY}_{\mathrm{CURD}}$, as well as for the high-throughput laboratory cheesemaking protocol $(1.7 \mathrm{~mL} /$ sample) proposed by Bachmann et al., (2009). However, the latter method was not used to measure $\% \mathrm{CY}$, but rather to test cheese starter cultures. In some cases, the authors have reported the weights of both fresh and dried curds. Macheboeuf et al. (1993) evalu- ated the effects of the breed (Holstein, Tarentaise, and Montbeliarde), genetic protein variants, and feeding system on individual milk samples $(20 \mathrm{~mL})$ produced by 137 cows in different seasons. They obtained very high $\% \mathrm{CY}_{\text {CURD }}$ values $(>30 \%)$ because of a very high water retention in curd. Accordingly, they corrected $\% \mathrm{CY}_{\text {CURD }}$ to a curd DM content of $30 \%$, as proposed by Maubois and Mocquot (1967), but still observed high average values of this trait. Melilli et al. (2002)

Table 6. For the repeatability trial, ANOVA and repeatability of cheese yield traits (\%CY) and milk nutrients recovery in the curd (REC, \%) measured by $9-$ MilCA $^{1}$ method $^{2}$

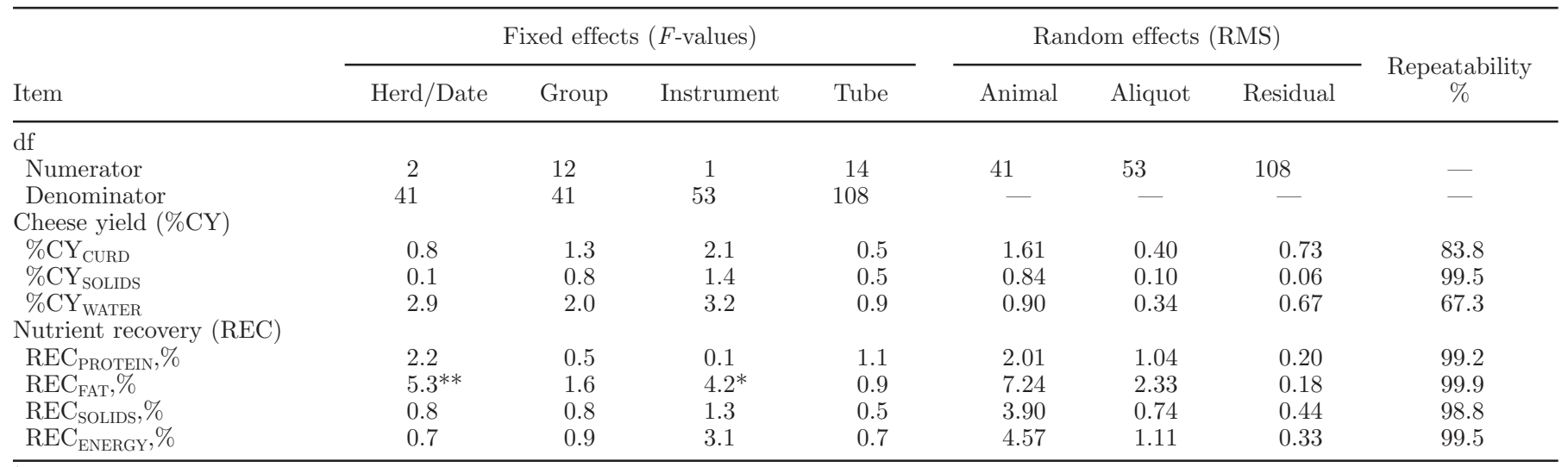

${ }^{1}$ 9-MilCA $=9$-mL milk cheesemaking assessment.

${ }^{2} \% \mathrm{CY}_{\mathrm{CURD}}=$ fresh cheese yield; $\% \mathrm{CY}_{\text {SOLIDS }}=$ total solids cheese yield; $\% \mathrm{CY}_{\mathrm{WATER}}=$ water retained in the curd; $\mathrm{REC} \mathrm{PROTEIN}_{\mathrm{P}}, \%=$ protein retention; $\mathrm{REC}_{\mathrm{FAT}}, \%=$ fat retention; $\mathrm{REC}_{\mathrm{SOLIDS}}, \%=$ total solids retention; $\mathrm{REC}_{\mathrm{ENERGY}}, \%=$ energy retention.

$* P<0.05 ; * * P<0.01$ 
described a very efficient protocol that involved the use of $10-\mathrm{mL}$ milk samples. They recorded only the dry weight of curd, obtained through centrifugation, and found a high correlation with the $\% \mathrm{CY}_{\mathrm{CURD}}$ estimated using the formula proposed by Van Slyke and Publow (1910), which considers the milk protein and fat recoveries in the curd to be constant.

Table 6 presents the results of ANOVA for the cheesemaking measures obtained in our repeatability trial. The variability among the individual animals within the herd or test date and group was very large, reflecting differences in breed, parity, DIM, and milk yield. The individual animal explained a high proportion of the total variance (animal plus aliquot plus residual variance; $59,84,47,62,74,77$, and $76 \%$ for $\% \mathrm{CY}_{\mathrm{CURD}}$, \% $\mathrm{CY}_{\text {SOLIDS }}, \quad \% \mathrm{CY}_{\text {WATER }}, \quad \mathrm{REC}_{\text {PROTEIN }}, \mathrm{REC}_{\mathrm{FAT}}$, $\mathrm{REC}_{\text {SOLIDS }}$, and $\mathrm{REC}_{\mathrm{ENERGY}}$, respectively).

The animal standard deviation was slightly less than one percentage point for $\% \mathrm{CY}_{\text {SOLIDS }}$ and $\% \mathrm{CY}_{\text {WATER }}$ (Table 3), and it was 1.61 for their sum $\left(\% \mathrm{CY}_{\mathrm{CURD}}\right)$. The animal standard deviation was much larger for the REC traits, ranging from 2 percentage points for $\mathrm{REC}_{\text {PROTEIN }}$ to more than 7 percentage points for $\mathrm{REC}_{\mathrm{FAT}}$. These values are slightly greater than the residual standard deviations reported for the model cheesemaking trait measures obtained using 1,500-mL milk samples from 1,167 individual Brown Swiss cows (Cipolat-Gotet et al., 2013). Cipolat-Gotet et al. (2013) involved only one value per cow, so the residual standard deviations of the different cheesemaking traits combined the effect of animal variability with that caused by the repeatability of the trait. However, the proportions of the 2 sources of residual variation cannot be known. Moreover, unlike in the previous study, the statistical model used in the present work did not include the effects of parity, DIM, and breed, which contribute to animal variance.

Macheboeuf et al. (1993) obtained much greater residual standard deviations when examining $\% \mathrm{CY}_{\mathrm{CURD}}$ and $\% \mathrm{CY}_{\mathrm{CURD}}$ corrected to $30 \% \mathrm{DM}$ (4.8 and 2.7 percentage points, respectively). No apparent reason for the greater animal variability was noted, so this seems likely to reflect that the adopted technique yielded a very moist curd ( $77 \%$ moisture) that was characterized by a very high average $\% \mathrm{CY}_{\mathrm{CURD}}$ and (possibly) low repeatability.

The large between-animal variability observed for these traits contradicts the assumption that the fat and protein recoveries are constant, even though such assumptions are made in many equations used to estimate $\% \mathrm{CY}_{\mathrm{CURD}}$ (Emmons et al., 1990) and in some laboratory-level individual cheesemaking protocols (Melilli et al., 2002). Indeed, this large individual variability is the basis for the demonstrated heritability of cheesemaking traits (Bittante et al., 2013a, 2014a) and the consequent need for their inclusion in the selection objectives of dairy cow breeding schemes (Cecchinato et al., 2015). In the present work, the effects of herd or date and group (5 groups of 4 cows per day), both of which were tested on random animal variance, identified the portions of the trait variability that were related to the sampling of farms and cows (and were therefore not directly related to the proposed protocol). Only $\mathrm{REC}_{\mathrm{FAT}}$ was affected by herd or date $(P<0.01)$. Notably, only 1 herd was sampled for each cheesemaking day, so this effect also included the variability related to the breed's proportion of the herd, as well as milk collection, milk transportation, and sample preparation.

The reproducibility of the 9-MilCA method was tested by comparing the different instruments $(\mathrm{n}=2)$ and the different tube positions within each instrument $(\mathrm{n}=8)$. The random effect of the 2 aliquots of each individual cow milk sample was used to compare the 2 instruments and presented standard deviation values considerably lower than those expressed by animal: from about one-half for $\mathrm{REC}_{\text {PROTEIN }}$ to about one-eighth for $\% \mathrm{CY}_{\text {SOLIDS. }}$. This source of variation represented the effect of the sampling aliquot, the interval between the sampling of the milk and processing within the instrument, the operations carried out by the technician to prepare the sample for analysis, and the repeatability of the composition analyses of the milk and whey.

The instrument effect, which was tested on aliquot variance, presented a significant effect only for $\mathrm{REC}_{\mathrm{FAT}}$ $(P<0.05)$, yielding an almost negligible difference between the least squares means of the 2 instruments. The glass tube position (within instrument) was tested on the residual variance (the variance of different replicates of each aliquot within instrument) and was not significant for any trait. This differed from our findings for the $\mathrm{MCP}-\mathrm{CF}_{\mathrm{t}}$ traits and confirmed the good reproducibility of the 9-MilCA method.

The residual standard deviation was much smaller than the aliquot one (from about one-half to onetwelfth; Table 3), with the notable exceptions of $\% \mathrm{CY}_{\text {WATER }}$ and $\% \mathrm{CY}_{\mathrm{CURD}}$, which showed residual standard deviations almost double that of the aliquot. As with the statistical model adopted for the present trial, the residual variance identified the variability between the 2 replicates within each instrument, corrected for the effect of glass tube position; it could thus be used as a measure of protocol repeatability. In the case of the $4 \mathrm{REC}$ traits and $\% \mathrm{CY}_{\text {SoLiDS }}$, the residual variances represented only about $1 \%$ of each total variance, yielding repeatability values of about $99 \%$ for these traits. In the case of $\% \mathrm{CY}_{\mathrm{WATER}}$, in contrast, the variability between replicates was larger and the repeatability of 
Table 7. For the centrifuging trial, descriptive statistics and results of Levene's test for heteroskedasticity of residual variance of cheese yield traits (\%CY) and milk nutrients recovery in the curd (REC, \%) measured on 9-mL milk samples after coagulum centrifugation or by using 9-MilCA ${ }^{1}$ method (96 cheesemakings: 3 groups $\times 4$ cows each $\times 2$ methods $\times 2$ instruments $\times 2$ replicates $/$ vats $)^{2}$

\begin{tabular}{|c|c|c|c|c|c|}
\hline \multirow[b]{2}{*}{ Item } & \multicolumn{2}{|c|}{ Centrifugation } & \multicolumn{2}{|c|}{ 9-MilCA } & \multirow{2}{*}{$\begin{array}{l}\text { Levene's test } \\
\quad(P \text {-value })\end{array}$} \\
\hline & Average & $\mathrm{SD}$ & Average & $\mathrm{SD}$ & \\
\hline \multicolumn{6}{|c|}{ Cheese yield (\%CY) } \\
\hline$\% \mathrm{CY}_{\mathrm{CURD}}$ & 28.90 & 3.55 & 16.63 & 1.87 & $* * *$ \\
\hline$\% \mathrm{CY}_{\text {SOLIDS }}$ & 8.53 & 0.90 & 7.30 & 0.80 & $* * *$ \\
\hline$\% \mathrm{CY}_{\text {WATER }}$ & 20.36 & 2.84 & 9.33 & 1.28 & $* * *$ \\
\hline \multicolumn{6}{|c|}{ Nutrient recovery (REC) } \\
\hline $\mathrm{REC}_{\text {PROTEIN }}, \%$ & 79.23 & 2.24 & 76.26 & 2.01 & $* * *$ \\
\hline $\mathrm{REC}_{\mathrm{FAT}}, \%$ & 92.21 & 2.42 & 85.22 & 4.46 & $*$ \\
\hline $\mathrm{REC}_{\text {SOLIDS }}, \%$ & 60.81 & 3.51 & 52.04 & 3.40 & $* * *$ \\
\hline $\mathrm{REC}_{\text {ENERGY }}, \%$ & 72.86 & 3.31 & 65.79 & 3.26 & $* * *$ \\
\hline
\end{tabular}

${ }^{1}$ 9-MilCA: 9-mL milk cheesemaking assessment.

${ }^{2} \% \mathrm{CY}_{\mathrm{CURD}}=$ fresh cheese yield; $\% \mathrm{CY}_{\mathrm{SOLIDS}}=$ total solids cheese yield; $\% \mathrm{CY}_{\mathrm{WATER}}=$ water entrapped in the curd; $\mathrm{REC}_{\mathrm{PROTEIN}}, \%=$ protein retention; $\mathrm{REC}_{\mathrm{FAT}}, \%=$ fat retention; $\mathrm{REC}_{\mathrm{SOLIDS}}, \%=$ total solids retention; $\mathrm{REC}_{\text {ENERGY }}, \%=$ energy retention.

$* P<0.05 ; * * * P<0.001$.

the measure was smaller (Table 6). The water retention in the curd, together with $\% \mathrm{CY}_{\text {SOLIDS }}$, contributes to $\% \mathrm{CY}_{\mathrm{CURD}}$ and largely affects its repeatability.

Considering the modest reproducibility and repeatability often found for MCP obtained using lactodynamographs (Caroli et al., 1990), the above analyses show that our developed method yielded very good results for the measured cheesemaking traits. Only the measurement of curd syneresis through whey draining showed poorer (i.e., only moderate) repeatability. Our protocol could be improved in this regard in the future. Until then, replicated measurements will be essential if $\% \mathrm{CY}_{\mathrm{WATER}}$ and $\% \mathrm{CY}_{\mathrm{CURD}}$ are of interest.

\section{Centrifugation Trial: Comparison of Curd and Whey Separation Techniques}

The third experiment (Table 7) was carried out to compare the 9-MilCA protocol with a simpler procedure in which the coagulum was centrifuged in place of the curd cutting, cooking, or draining steps. The former strategy is often applied in laboratory cheesemaking methods that use small milk samples $(\leq 50 \mathrm{~mL}$; Macheboeuf et al., 1993; Melilli et al., 2002; Othmane et al., 2002). The choice to use the cutting, cooking, or draining steps is also related to reduce as much as possible the mechanical treatments allowing a natural syneresis of the clot. Actually, our protocol does not allow to calculate an instant rate syneresis but some of the traits (REC and \% CY WATER $_{\text {) }}$ could be useful to give an evaluation of this process. This trial was carried out also to test the repeatability of syneresis comparing the 2 procedures.
Table 7 presents the mean values and standard deviations of the cheesemaking traits obtained using the 2 methods, along with the results obtained using Levene's test for variance homogeneity. The 2 protocols were found to be heteroskedastic for all of the considered traits, and thus could not be jointly analyzed or compared. However, it is evident from Table 7 that centrifugation yielded much greater average values for all of the examined traits.

The largest difference between the 2 procedures was observed for water retention in the curd: $\% \mathrm{CY}_{\text {WATER }}$ was more than doubled by centrifugation compared with the curd cutting-, cooking-, or draining-based method. Centrifugation also increased \% CY through increases in all of the REC traits. This reflected the greater proportion of whey and whey solids (whey proteins, lactose, fat, and minerals) retained in the centrifuged curd, due to the inefficient separation of solids from the whey. Regarding the residual within-method variance, centrifugation was characterized by much greater values for the \%CY traits (low repeatability) in proportion to its effect on the average values. Meanwhile, smaller values were found for the REC traits, reflecting that the separation of different nutrients is relatively standard and is due more to their physicochemical properties than to the interaction between milk and rennet.

The centrifugation used in this work $(1,800 \times g$, $20^{\circ} \mathrm{C}, 15 \mathrm{~min}$ ) was similar to the protocols found in other studies (Othmane et al., 2002; Melilli et al., 2002) and yielded similar very high $\% \mathrm{CY}_{\mathrm{CURD}}$ estimates that reflected the high-level retention of water. A more intense centrifugation (in timing or speed) was tested during protocol development. However, it was found 
effective in decreasing water retention but further increasing the recovery of milk nutrients (especially fat), producing a relation of cheesemaking traits with the chemical composition of the milk sample more than with its technological cheesemaking properties.

\section{Representativeness Trial Comparing the 9-MilCA Method with a Model Cheese Production Procedure}

In the fourth experiment, we compared \%CY and REC traits obtained from 9-MilCA versus those obtained from a laboratory model cheesemaking process that uses $1,500-\mathrm{mL}$ milk samples and is more similar to dairy plant practice. This model cheesemaking method was used by Cipolat-Gotet et al. (2013) to process individual milk samples $(\mathrm{n}=1,167)$ from Brown Swiss cows reared in the same area as the cows sampled in the current study (Trento Province). Cipolat-Gotet et al. (2013) assessed the sources of variation for cheesemaking traits (\%CY and REC), in relation to cow characteristics (DIM and order of parity). Other studies (Hicks et al., 1981; O'Callaghan et al., 2002) have used laboratory simulations of cheesemaking processes that required large quantities of milk $(\geq 500 \mathrm{~mL}$ per sample), examined a small number of samples per session, and involved several manual operations performed on individual samples (detection of clotting time, curd cutting, separation of the curd from the whey, and wheel shaping, pressing, and salting).

Table 8 presents descriptive statistics for the $\% \mathrm{CY}$ and REC traits obtained from 9-MilCA and the model cheese procedures. Our results revealed that 9-MilCA did, indeed, meet our objective of obtaining average cheesemaking traits similar to those achieved with the more complex procedure. As far fewer samples could be analyzed per day and a greater work-time was required, we did not obtain model cheese replicates or test the homogeneity of residual variances. Notably Cologna et al. (2009) tested a similar model cheese procedure and found that $\% \mathrm{CY}_{\mathrm{CURD}}$ was not affected by laboratorybased causes of variation (i.e., the water bath and the vat within the water bath) and observed a residual standard deviation similar to that obtained herein for the 9-MilCA protocol (the other cheesemaking traits were not available). The largest differences between the standard deviations of 9-MilCA versus the model cheese protocol were seen in $\% \mathrm{CY}_{\mathrm{WATER}}$ and (consequently) $\% \mathrm{CY}_{\mathrm{CURD}}$, which were both greater for the model cheese protocol than for 9-MilCA (Table 8).

Table 9 summarizes the results from the ANOVA. Beyond the expected differences among the different herd or dates and the high variability explained by the animal effect, the method (and its interaction with herd or date) showed few significant differences between the 2 procedures. This reflects the low values exhibited by the model residuals, as the absolute between-method differences in the least squares means were $0.3,0.1$, $0.2,0.3,0.8$, and $1.7 \%$ for $\% \mathrm{CY}_{\mathrm{CURD}}, \% \mathrm{CY}_{\text {SOLIDS }}$, $\% \mathrm{CY}_{\text {WATER }}, \mathrm{REC}_{\text {PROTEIN }}, \mathrm{REC}_{\mathrm{FAT}}, \mathrm{REC}_{\mathrm{SOLIDS}}$, and RE$\mathrm{C}_{\text {ENERGY }}$, respectively (data not shown).

Table 10 shows a regression of experimental data obtained from the same 12 individual milk samples processed using all 3 cheesemaking protocols (9-Mil$\mathrm{CA}$, cheesemaking with coagulum centrifugation, and model cheese production procedure) for each cheesemaking trait. We first compared the results obtained

Table 8. For the representativeness trial, descriptive statistics of cheese yield traits (\%CY) and milk nutrients recovery in the curd (REC, \%) measured using 9-MilCA (9-mL milk cheesemaking assessment) or model-cheese procedure on 1,500-mL milk samples (144 cheesemakings: 4 cheesemaking sessions $\times 5^{1}$ groups of cows $\times 4$ cows each $\times 2$ methods $\left.^{2}\right)^{3}$

\begin{tabular}{|c|c|c|c|c|}
\hline \multirow[b]{2}{*}{ Item } & \multicolumn{2}{|c|}{ 9-MilCA } & \multicolumn{2}{|c|}{ Model cheeses } \\
\hline & Average & $\mathrm{SD}$ & Average & $\mathrm{SD}$ \\
\hline \multicolumn{5}{|c|}{ Cheese yield (\%CY) } \\
\hline$\% \mathrm{CY}_{\mathrm{CURD}}$ & 15.38 & 1.84 & 15.10 & 2.31 \\
\hline$\% \mathrm{CY}_{\text {SOLIDS }}$ & 6.50 & 0.87 & 6.42 & 0.84 \\
\hline$\% \mathrm{CY}_{\text {WATER }}$ & 8.88 & 1.19 & 8.68 & 1.65 \\
\hline \multicolumn{5}{|c|}{ Nutrient recovery (REC) } \\
\hline REC $_{\text {PRoteIN }}, \%$ & 77.13 & 2.16 & 76.77 & 2.27 \\
\hline $\mathrm{REC}_{\mathrm{FAT}}, \%$ & 81.70 & 8.02 & 82.45 & 6.51 \\
\hline $\mathrm{REC}_{\text {SOLIDS }}, \%$ & 49.21 & 3.92 & 48.55 & 3.58 \\
\hline REC $_{\text {ENERGY }}, \%$ & 62.29 & 4.60 & 64.24 & 3.98 \\
\hline
\end{tabular}

${ }^{1}$ One cheesemaking session with only 3 groups of cows.

${ }^{2}$ In the case of 9-MilCA, each datum was the average of 2 replicates, whereas for model cheeses no replicates were available.

${ }^{3} \% \mathrm{CY}_{\mathrm{CURD}}=$ fresh cheese yield; $\% \mathrm{CY}_{\mathrm{SOLIDS}}=$ total solids cheese yield; $\% \mathrm{CY}_{\mathrm{WATER}}=$ water entrapped in the curd; $\mathrm{REC}_{\mathrm{PROTEIN}}, \%=$ protein retention; $\mathrm{REC}_{\mathrm{FAT}}, \%=$ fat retention; $\mathrm{REC}_{\text {SOLIDS }}, \%=$ total solids retention; $\mathrm{REC}_{\text {ENERGY }}, \%=$ energy retention. 
Table 9. For the representativeness trial, ANOVA of cheese yield traits (\%CY) and milk nutrients recovery in the curd (REC, \%) measured on 9 -mL milk samples using modified lactodynamographs and simultaneously recoding milk coagulation properties, or on 1,500-mL milk samples using water baths, individual vats, and model cheese procedure ${ }^{1}$

\begin{tabular}{|c|c|c|c|c|c|}
\hline df & \multicolumn{3}{|c|}{ Fixed effects ( $F$-values) } & \multicolumn{2}{|c|}{ Random effects (RMS) } \\
\hline Numerator & 3 & 1 & 3 & 67 & 67 \\
\hline$\% \mathrm{CY}_{\mathrm{CURD}}$ & $4.82^{* *}$ & $4.42^{*}$ & $11.50^{* * *}$ & 1.72 & 0.83 \\
\hline$\% \mathrm{CY}_{\text {SOLIDS }}$ & $4.05^{*}$ & $7.62^{* *}$ & $4.68^{* *}$ & 0.77 & 0.22 \\
\hline$\% \mathrm{CY}_{\text {WATER }}$ & $6.75^{* * *}$ & 2.52 & $11.68^{* * *}$ & 1.05 & 0.71 \\
\hline $\mathrm{REC}_{\text {ENERGY }}, \%$ & 2.50 & $20.09^{* * *}$ & $4.38^{* *}$ & 3.48 & 2.25 \\
\hline
\end{tabular}

${ }_{1} \% \mathrm{CY}_{\mathrm{CURD}}=$ fresh cheese yield; $\% \mathrm{CY}_{\text {SOLIDS }}=$ total solids cheese yield; $\% \mathrm{CY}_{\mathrm{WATER}}=$ water entrapped in the curd; $\mathrm{REC}$ PROTEIN,$\%=$ protein retention; $\mathrm{REC}_{\mathrm{FAT}}, \%=$ fat retention; $\mathrm{REC}_{\mathrm{SOLIDS}}, \%=$ total solids retention; $\mathrm{REC}_{\mathrm{ENERGY}}, \%=$ energy retention.

${ }^{*} P<0.05 ;{ }^{* *} P<0.01 ;{ }^{* * *} P<0.001$.

from 9-MilCA and the model cheese procedure. The $\% \mathrm{CY}_{\text {CURD }}$ showed a good agreement between the 2 procedures, as the coefficient of correlation was 0.80 and the intercept and slope $(-1.3 \%$ and 1.06 , respectively) were not significantly different from the expected values (0 and 1, respectively). Similar results were obtained for $\% \mathrm{CY}_{\text {SOLIDS }}, \mathrm{REC}_{\text {SOLIDS }}$, and $\mathrm{REC}_{\text {ENERGY }}$. Less concordance of the $\% \mathrm{CY}_{\text {WATER }}$ values was yielded by the 2 procedures $(r=0.54)$, although the intercept and slope were not significantly different from the expected values; this confirmed the lower repeatability of the syneresis trait. In contrast, the intercept and slope of the regression for $\mathrm{REC}_{\text {PROTEIN }}$ were significantly different from the expected values, even though the correlation between the 2 was very high $(\mathrm{r}=0.99)$ and the RMSE was very low $(0.27 \%)$. The opposite was observed for $\mathrm{REC}_{\mathrm{FAT}}$, which showed the greatest RMSE and larger (but not significant) variations of the intercept and slope from the expected values. The variability of fat recovery is well known, prompting some authors to remove the interference of fat from their analysis by using defatted milk samples (Glantz et al., 2011). However, fat recovery is economically important to the cheese industry.

Table 10 also summarizes the comparison of the $9-\mathrm{mL}$ centrifugation-based protocol with 9-MilCA and model cheese production procedure. As noted earlier, the use of centrifugation worsened the results with respect to the other methods. However, relatively good agreement was observed between the two 9-mL protocols in terms of the results, especially with regard to $\% \mathrm{CY}_{\text {WATER }}$ and $\mathrm{REC}_{\mathrm{FAT}}$.

\section{General Discussion}

We herein describe a protocol (9-MilCA) for a laboratory cheesemaking procedure that allows the simultaneous recording of the milk coagulation, curd firming, cheese yield, and curd nutrient recovery traits. The protocol uses instruments (heater and lactodynamograph) that are present in many laboratories and requires only an easy modification of the sample rack to enable the insertion of $10-\mathrm{mL}$ glass tubes. The procedure for evaluating milk coagulation and curd firming was modified only by the addition (after the curd firmness recording period) of a phase during which the obtained small curds were cut, cooked, and drained. The weighing and analysis of the processed milk and collected whey allowed us to obtain a complete material and energy balance for the cheesemaking.

The new protocol proved to be very efficient, allowing the processing of 40 milk samples per day with 2 replicates (using 1 lacto-dynamograph, 2 heaters, and 3 modified sample racks), and yielded very repeatable results for all considered traits, except for $\% \mathrm{CY}_{\mathrm{CURD}}$ and $\% \mathrm{CY}_{\text {WATER }}$. The use of centrifugation in place of curd cooking and draining reduced the efficiency of whey separation, led to the overestimation of all \%CY and REC traits, and worsened the repeatability of the measures. In contrast, our 9-MilCA method yielded results very similar to those obtained using a more complex model cheese-manufacturing process carried out on milk samples of $1,500 \mathrm{~mL}$.

The milk gelation and curd firming patterns recorded during 9-MilCA were very similar to those obtained from the unmodified procedure, with improvements seen in the repeatability of the coagulation and curd firming traits measured using the modified sample rack. The 9-MilCA procedure should be able to be adjusted to various research objectives. For example, if MCP are not of interest, the procedure could be performed using only the heater plate and the modified sample rack. In contrast, if prolonged MCP observation is required, MCP could be performed using a regular sample rack 


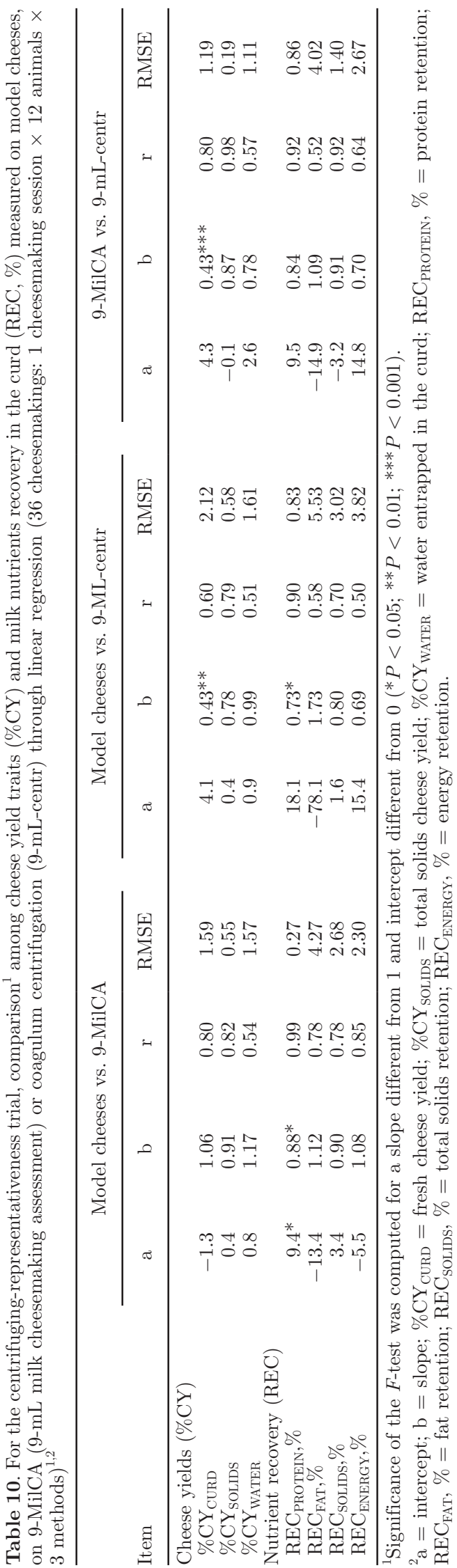

and the lacto-dynamograph for the desired duration, whereas $9-\mathrm{mL}$ cheeses could be obtained simultaneously using the modified sample rack and the heater plate.

\section{CONCLUSIONS}

In conclusion, the 9-MilCA method appears to be a powerful research tool that will allow the rapid and inexpensive analysis of a large number of milk samples, yielding a complete picture of the cheesemaking process (i.e., milk gelation, curd firming, syneresis and whey expulsion), as well as measures of cheese yield and energy or nutrients retention in the cheese.

\section{ACKNOWLEDGMENTS}

This research was supported by the University of Padova (Ricerca Scientifica fondi quota EX 60\% - 60A08$7943 / 14)$.

\section{REFERENCES}

Ali, A. K. A., and G. E. Shook. 1980. An optimum transformation for somatic cell concentration in milk. J. Dairy Sci. 63:487-490.

Annibaldi, S., G. Ferri, and R. Mora. 1977. Nuovi orientamenti nella valutazione tecnica del latte: Tipizzazione lattodinamografica. Sci. Tecn. Latt. Cas. 28:115-126.

Bachmann, H., Z. Kruijswijk, D. Molenaar, M. Kleerebezem, and J. E. T. van Hylckama Vlieg. 2009. A high-throughput cheese manufacturing model for effective cheese starter culture screening. J. Dairy Sci. 92:5868-5882.

Banks, J. M. 2007. Cheese yield. Pages 100-114 in Cheese Problems Solved. P. L. H. McSweeney, ed. Woodhead Publishing Ltd., Cambridge, UK.

Bittante, G. 2011. Modeling rennet coagulation time and curd firmness of milk. J. Dairy Sci. 94:5821-5832.

Bittante, G., C. Cipolat-Gotet, and A. Cecchinato. 2013a. Genetic parameters of different measures of cheese yield and milk nutrient recovery from an individual model cheese-manufacturing process. J. Dairy Sci. 96:7966-7979.

Bittante, G., B. Contiero, and A. Cecchinato. 2013b. Prolonged observation and modelling of milk coagulation, curd firming, and syneresis. Int. Dairy J. 29:115-123.

Bittante, G., A. Ferragina, C. Cipolat-Gotet, and A. Cecchinato. 2014a. Comparison between genetic parameters of cheese yield and nutrient recovery of whey losses traits measured from individual model cheese-making methods or predicted from unprocessed bovine milk samples using Fourier-Transform infrared spectroscopy. J. Dairy Sci. 97:6560-6572.

Bittante, G., M. Penasa, and A. Cecchinato. 2012. Invited review: Genetics and modeling of milk coagulation properties. J. Dairy Sci. 95:6843-6870.

Caroli, A., P. Bolla, G. Pagnacco, M. Rampilli, and L. Degano. 1990. Repeatability of milk clotting aptitude evaluated by lactodynamographic analysis. J. Dairy Res. 57:141-142.

Castillo, M., M. J. Jordan, A. Godoy, J. Laencina, and M. B. Lopez. 2000. Kinetics of syneresis in fresh goat cheese. Milchwissenschaft 55:566-569.

Cecchinato, A., A. Albera, C. Cipolat-Gotet, A. Ferragina, and G. Bittante. 2015. Genetic parameters of cheese yield and curd nutrient recovery or whey loss traits predicted using Fourier-transform infrared spectroscopy (FTIR) of samples collected during milk recording on Holstein, Brown Swiss and Simmental dairy cows. J. Dairy Sci. 98:4914-4927. 
Cipolat-Gotet, C., A. Cecchinato, M. De Marchi, and G. Bittante. 2013. Factors affecting variation of different measures of cheese yield and milk nutrients recovery from an individual model cheese manufacturing process. J. Dairy Sci. 96:7952-7965.

Cipolat-Gotet, C., A. Cecchinato, M. De Marchi, M. Penasa, and G. Bittante. 2012. Comparison between mechanical and near-infrared optical methods for assessing milk coagulation properties. J. Dairy Sci. 95:6806-6819.

Cologna, N., R. Dal Zotto, M. Penasa, L. Gallo, and G. Bittante. 2009 A laboratory micro-manufacturing method for assessing individual cheese yield. Ital. J. Anim. Sci. 8(Suppl. 2):393-395.

Dal Zotto, R., M. De Marchi, A. Cecchinato, M. Penasa, M. Cassandro, P. Carnier, L. Gallo, and G. Bittante. 2008. Reproducibility and repeatability of measures of milk coagulation properties and predictive ability of mid-infrared reflectance spectroscopy. J. Dairy Sci. 91:4103-4112.

Emmons, D. B., C. A. Ernstrom, C. Lacroix, and P. Verret. 1990 Predictive formulas for yield of cheese from composition of milk: A review. J. Dairy Sci. 73:1365-1394.

Fagan, C. C., M. Castillo, F. A. Payne, C. P. O'Donnell, M. Leedy, and D. J. O'Callaghan. 2007. Novel online sensor technology for continuous monitoring of milk coagulation and whey separation in cheesemaking. J. Agric. Food Chem. 55:8836-8844.

Glantz, M., H. Lindmark Mansson, H. Stalhammar, and M. Paulsson. 2011. Effect of polymorphisms in the leptin receptor, and acylcoenzyme A:diacylglycerol acyltransferase 1 (DGAT1) genes and genetic polymorphism of milk proteins on cheese characteristics. J. Dairy Sci. 94:3295-3304.

Hansen, C. L., A. Rinnan, S. B. Engelsen, T. Janhøj, E. Micklander, U. Andersen, and F. Van Den Berg. 2010. Effect of gel firmness at cutting time, $\mathrm{pH}$, and temperature on rennet coagulation and syneresis: An in situ H NMR relaxation study. J. Agric. Food Chem. $58: 513-519$.

Hicks, C. L., J. O'Leary, and B. E. Langlois. 1981. Equipment and procedure for manufacturing laboratory cheese curd. J. Dairy Sci. 64:523-525.

Ikonen, T., K. Ahlfors, R. Kempe, M. Ojala, and O. Ruottinen. 1999. Genetic parameters for the milk coagulation properties and prevalence of noncoagulating milk in Finnish dairy cows. J. Dairy Sci. $82: 205-214$.

Ikonen, T., S. Morri, A.-M. Tyrisevä, O. Routtinen, and M. Ojala. 2004. Genetic and phenotypic correlations between milk coagulation properties, milk production traits, somatic cell count, casein content, and pH of milk. J. Dairy Sci. 87:458-467.

Klandar, A. H., A. Lagaude, and D. Chevalier-Lucia. 2007. Assessment of the rennet coagulation of skim milk: A comparison of methods. Int. Dairy J. 17:1151-1160.

Laporte, M.-F., R. Martel, and P. Paquin. 1998. The near-infrared optic probe for monitoring rennet coagulation in cow's milk. Int. Dairy J. 8:659-666.
Macheboeuf, D., J. B. Coulon, and P. D'Hour. 1993. Effect of breed, protein genetic variants and feeding on cows' milk coagulation properties. J. Dairy Res. 60:43-54.

Martin, B., D. Pomies, P. Pradel, I. Verdier-Metz, and B. Remond. 2009. Yield and sensory properties of cheese made with milk from Holstein or Montbeliarde cows milked twice or once daily. J. Dairy Sci. 92:4730-4737.

Maubois, J.-L., and G. Mocquot. 1967. How to standardize TS of cheese batches for comparing the relative yield obtained from cheese milk. Rev. Lait. Fr. 239:15-18.

McMahon, D. J., and R. J. Brown. 1982. Evaluation of Formagraph for comparing rennet solutions. J. Dairy Sci. 65:1639-1642.

Melilli, C., J. M. Lynch, S. Carpino, D. M. Barbano, G. Licitra, and A. Cappa. 2002. An empirical method for prediction of cheese yield. J. Dairy Sci. 85:2699-2704.

Milesi, M. M., M. Candiaoti, and E. Hynes. 2007. Mini soft cheese as a simple model for biochemical studies on cheese-making and ripening. Lebenson. Wiss. Technol. 40:1427-1433.

Milliken, G. A., and D. E. Johnson. 1984. Levene's test. Pages 19-25 in Analysis of Data. Vol. 1. Designed Experiments. Lifetime Learning Publ., Belmont, CA.

O'Callaghan, D. J., C. P. O'Donnell, and F. A. Payne. 2002. Review of systems for monitoring curd setting during cheesemaking. Int. J. Dairy Technol. 55:65-67.

Othmane, M. H., J. A. Carriedo, L. F. de la Fuente Crespo, and F. San Primitivo. 2002. An individual laboratory cheese-making method for selection in dairy ewes. Small Rumin. Res. 45:67-73.

Renault, C., E. Gastaldi, A. Lagaude, J. L. Cuq, and B. T. De La Fuente. 1997. Mechanisms of syneresis in rennet curd without mechanical treatment. J. Food Sci. 62:907-910.

Stocco, G., C. Cipolat-Gotet, A. Cecchinato, L. Calamari, and G. Bittante. 2015. Milk skimming, temperature, acidification, lysozyme, and rennet affect the pattern, repeatability and predictability of milk coagulation properties and of curd firming model parameters: the case-study of Grana Padano. J. Dairy Sci. 98:5052-5067.

Taifi, N., F. Bakkali, B. Faiz, A. Moudden, G. Maze, and D. Dècultot. 2006. Characterization of the syneresis and the firmness of the milk gel using an ultrasonic technique. Meas. Sci. Technol. $17: 281-287$

Tyrisevä, A.-M., T. Vahlsten, O. Ruottinen, and M. Ojala. 2004 Noncoagulation of milk in Finnish Ayrshire and Holstein-Friesian cows and effect of herds on milk coagulation ability. J. Dairy Sci 87:3958-3966.

Van Slyke, L. L., and C. A. Publow. 1910. The Science and Practice of Cheese Making. Orange Judd Company, New York, NY.

Verdier-Metz, I., J. B. Coulon, P. Pradel, C. Viallon, H. Albouy, and J. L. Berdagué. 2000. Effect of the botanical composition of hay and casein genetic variants on the chemical and sensory characteristics of ripened Saint-Nectaire type cheeses. Lait 80:361-370. 